\title{
THE FACT THAT THE EDUCATIONAL SUPERVISORS IN THE SULTANATE OF OMAN HAVE KNOWN THE EVOLUTIONARY SUPERVISION STYLE AND THE EXTENT OF THEIR APPLICATION FROM THEIR POINT OF VIEW
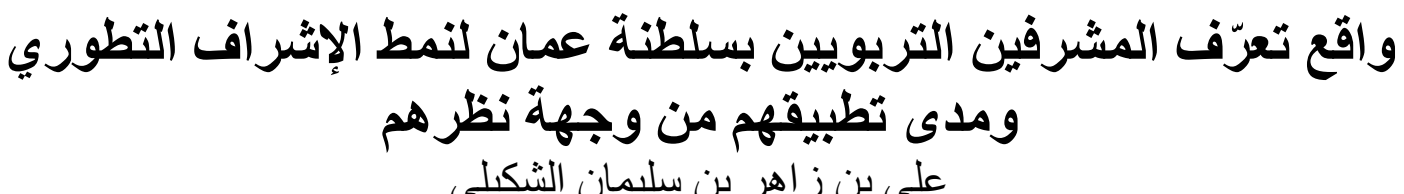

Ali Zahir Sulieman Alshukaili ${ }^{1 \star} \&$ Ismail Hussein Amzat ${ }^{2}$

${ }^{1} \mathrm{Ph}$. D. Candidate at the Faculty of Education, International Islamic University of Malaysia (IIUM); Ali.shukaili@moe.om

${ }^{2}$ Prof. Dr. at the Faculty of Education, International Islamic University of Malaysia (IIUM).

${ }^{*}$ Corresponding Author

\begin{abstract}
This study aimed to reveal the reality of educational supervisors in the Sultanate of Oman recognizing the evolutionary supervisory pattern and the extent of their application from their point of view, as well as revealing the impact of the study variables (gender, years of experience) in it, and the researcher used the descriptive approach, where a questionnaire was built to measure the educational supervisors' recognition in the Sultanate of Oman For the evolutionary supervision pattern and the extent of their application from the point of view of the supervisors themselves, the tool consisted of (21) paragraphs, distributed in two areas: the domain of the knowledge side (9) paragraphs, and the field of the applied side (12) paragraphs. The members of the study sample were randomly chosen. The study sample consisted of (285) supervisors and supervisors, who represent educational supervisors and educational supervisors in all educational directorates in the Sultanate of Oman. The results of the study showed that the reality of the educational supervisors' awareness (as a whole) in the Sultanate of Oman of the evolutionary supervision style from the point of view of the educational supervisors was (average). And the reality of the application of educational supervisors (as a whole) in the Sultanate of Oman to the evolutionary supervision style from the point of view of educational supervisors was (high). The results also showed that there were no statistically significant differences at the level of significance $(\alpha=0.05)$ between the averages (as a whole) and their fields from the point of view of the educational supervisors due to the variable (gender). And the presence of statistically significant differences at the level of significance $(\alpha=0.05)$ between the averages (as a whole) and their fields from the point of view of educational supervisors due to the variable (experience) and in favor of a group more than 15 years.
\end{abstract}

Keywords: Reality of supervision, educational supervisors, evolutionary supervision style. 
هدفت هذه الدراسة الكثف عن واقع تعرّف المشرفين التربوين بسلطنة عمان لنمط الإشرافي

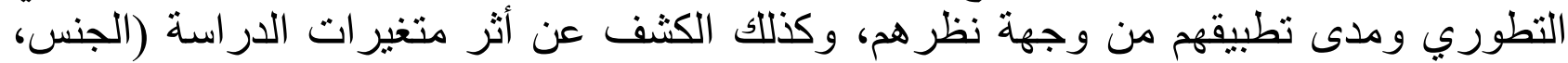

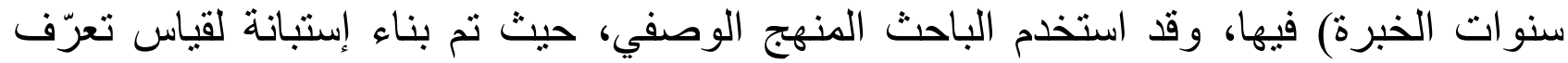

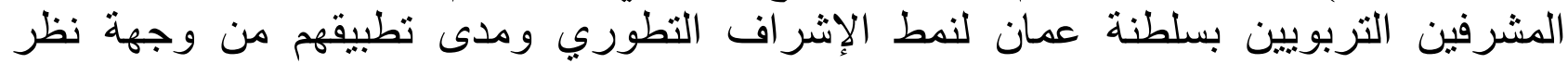

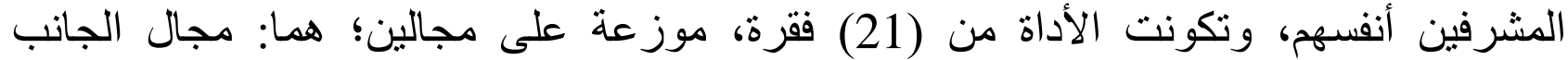

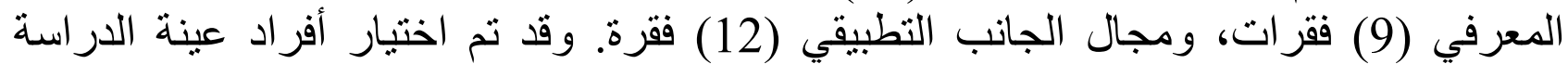

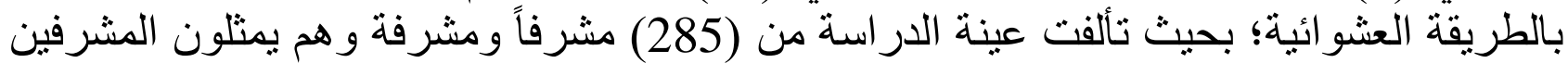

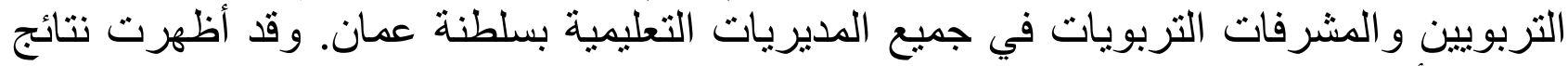

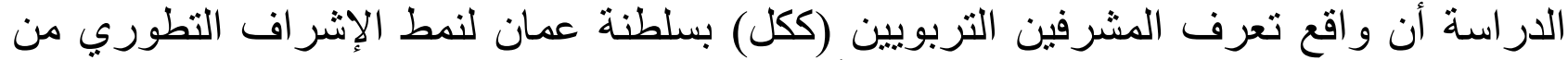

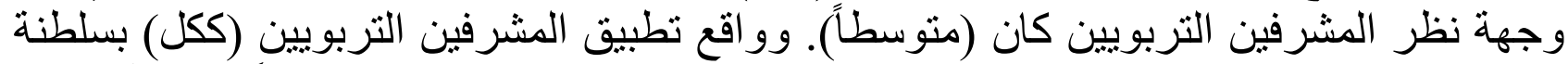

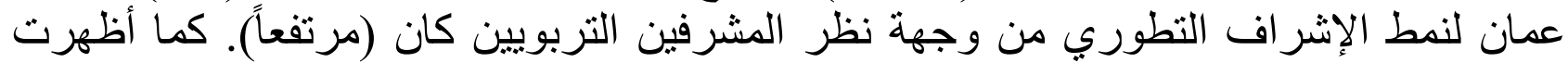

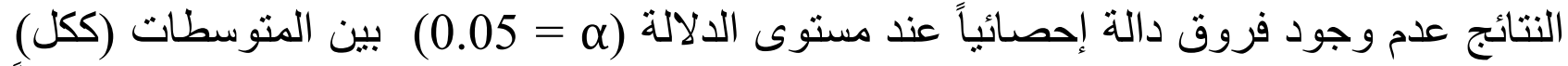

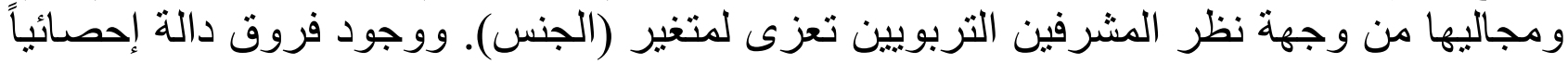

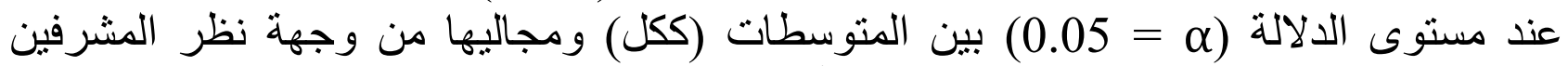

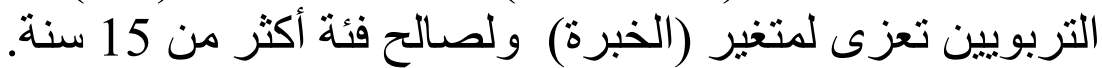

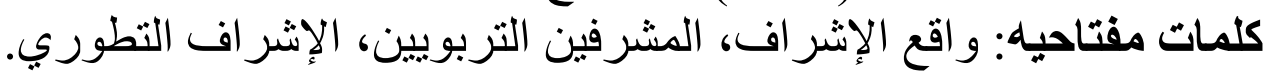

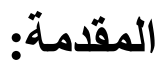

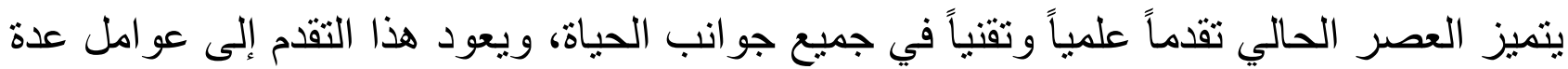

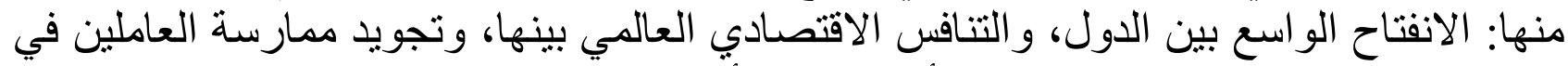

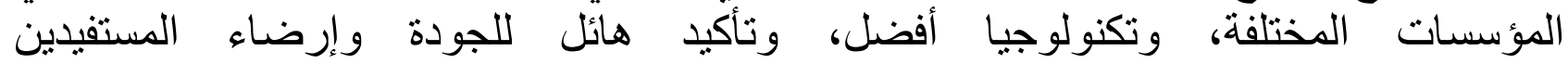

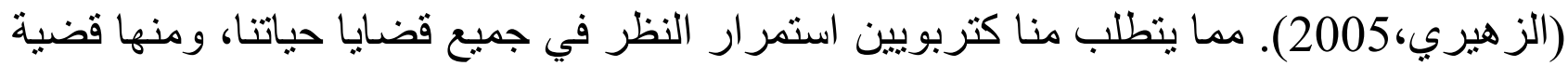

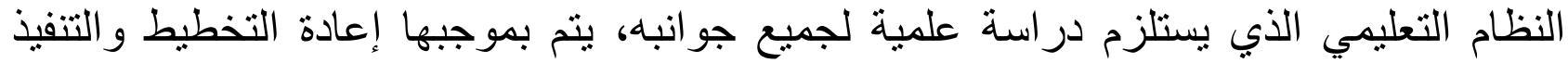
و التطوير في مجالات متعددة.

ويعتبر الإشراف التربوي من أهم عناصر العملية التعليمية كما تشير إليه جميع الأنظمة التعليمية

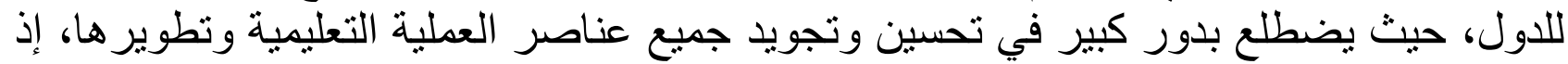

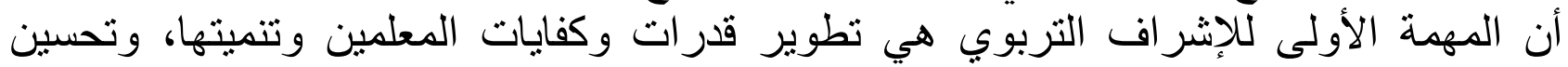

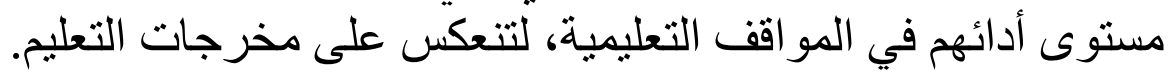

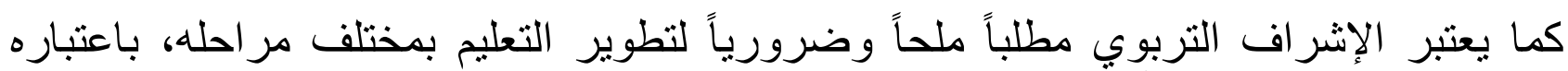

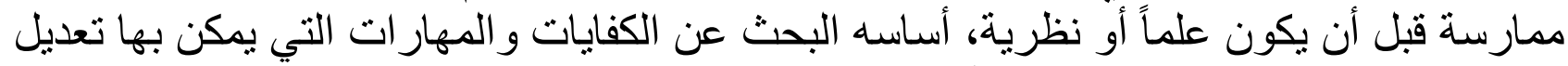

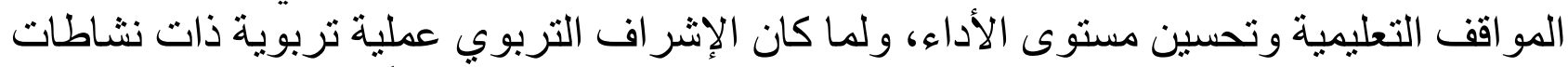

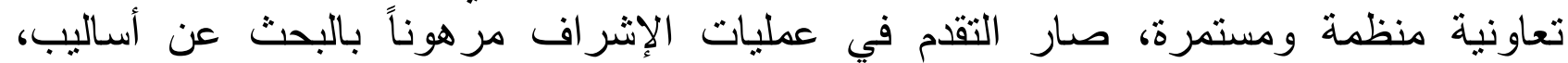

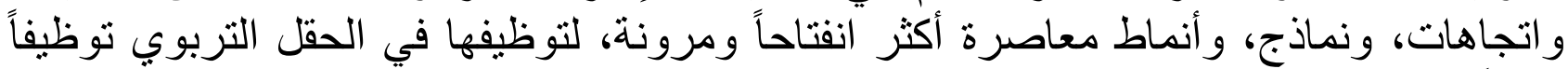

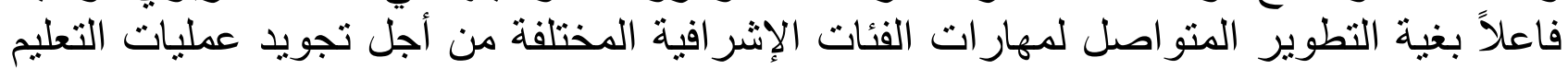

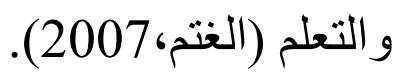




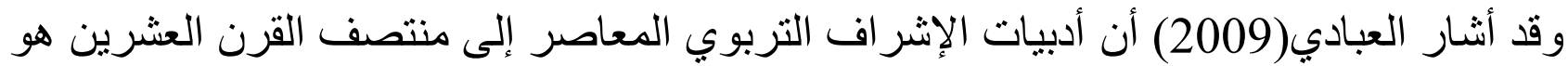

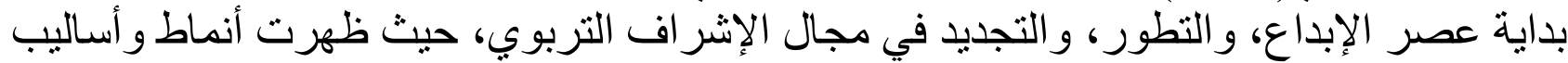

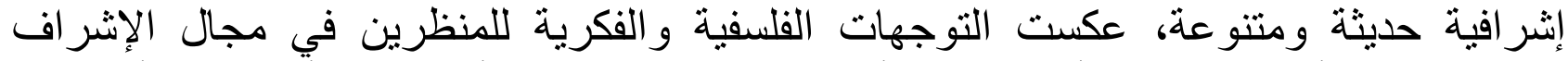

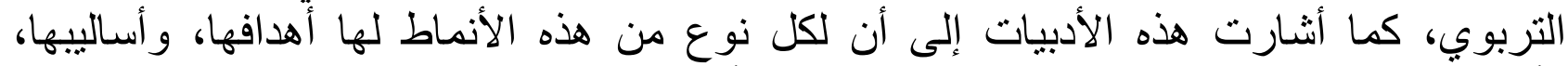

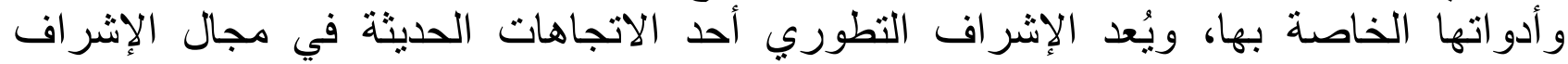

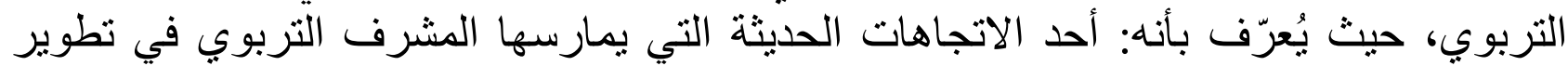

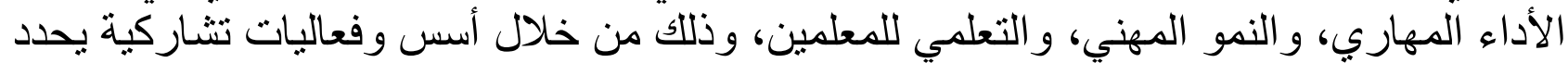

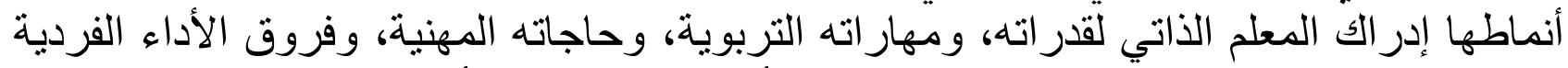

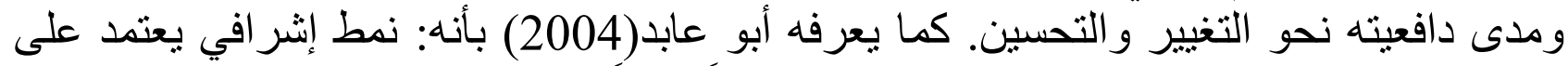

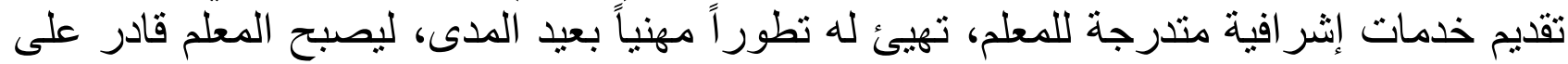

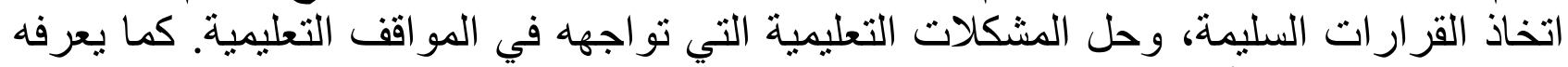

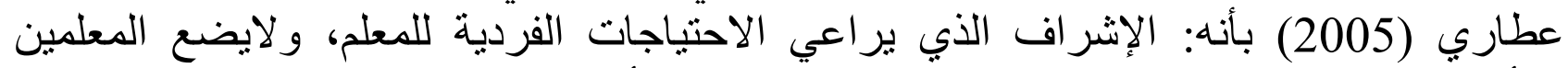

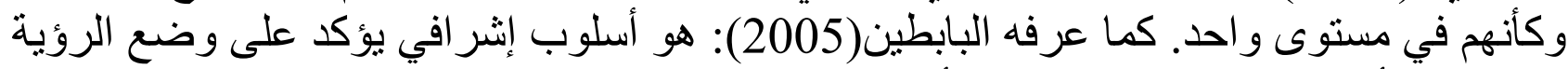

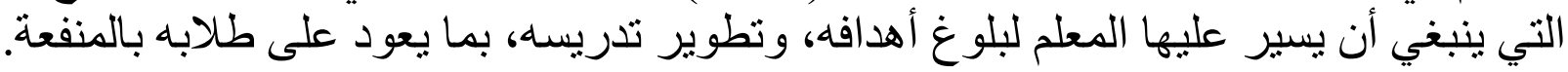

ويعرفه الباحث إجرائيا: هو الأسلوب الذي يهتم ويراعي الفروق الفردية بين المعلمين، ويعمل

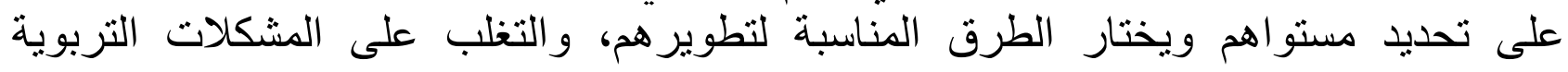

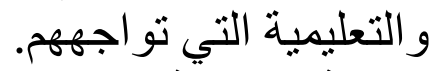

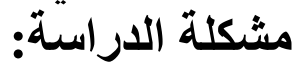

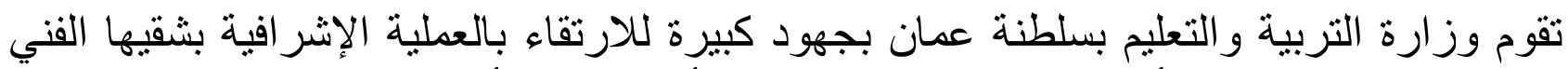

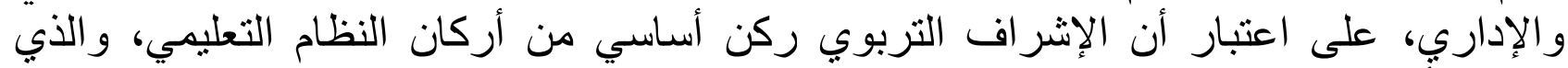

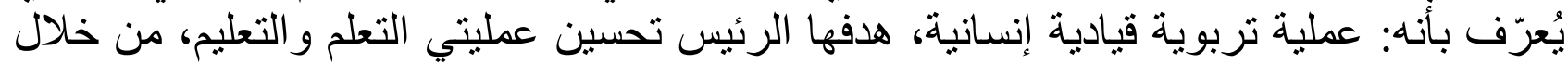

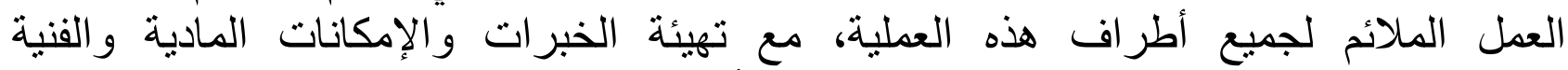

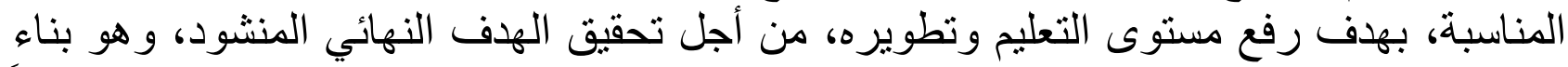

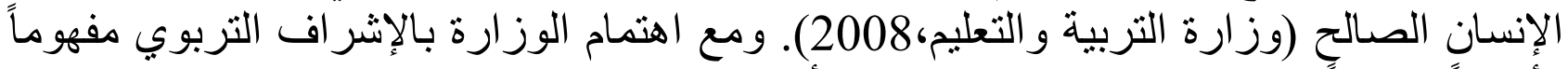

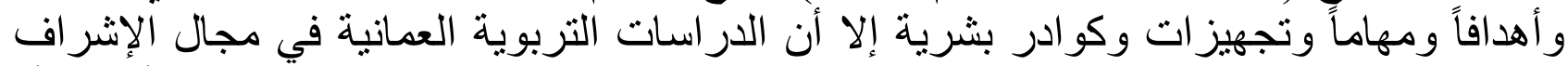

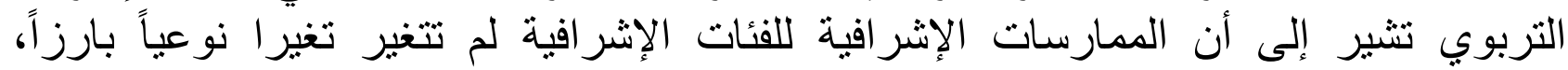

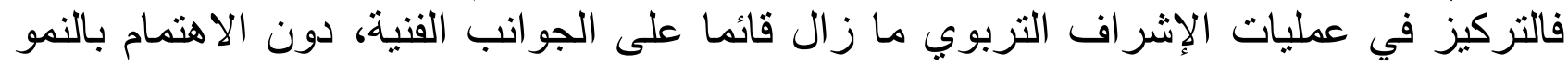

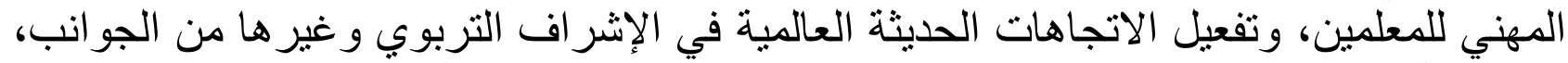

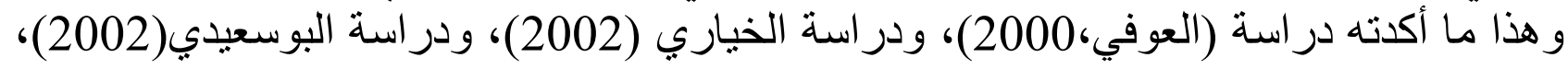

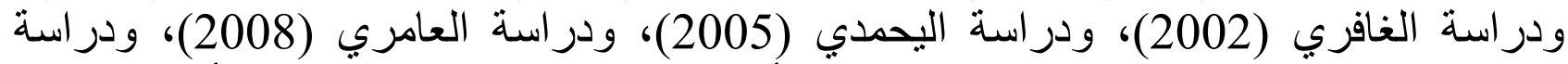

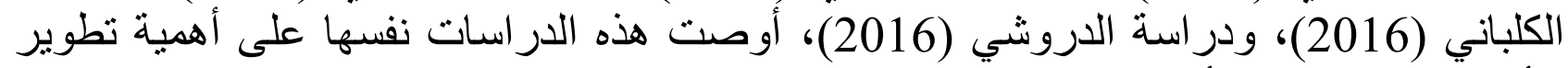

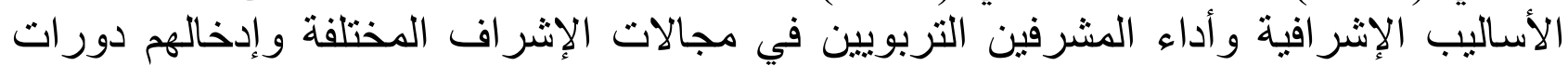
متخصصة.

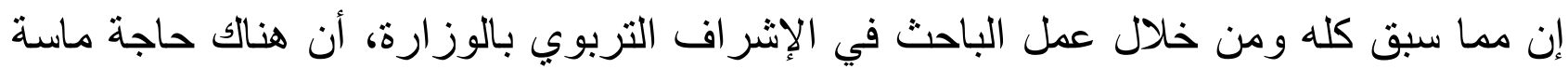

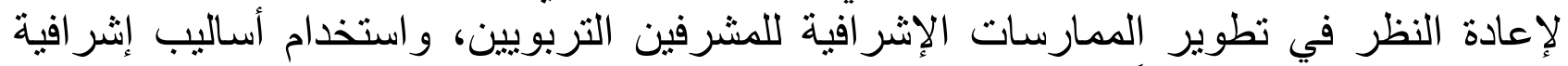

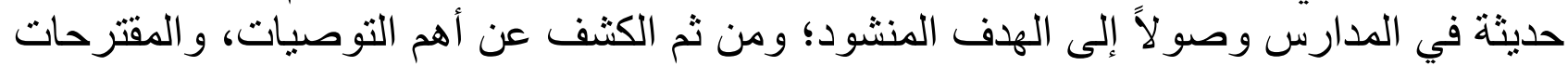




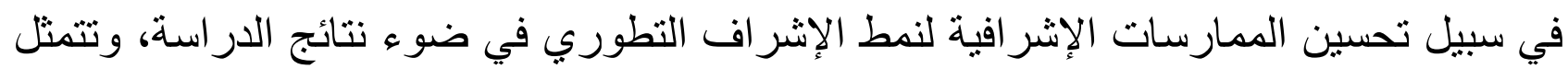

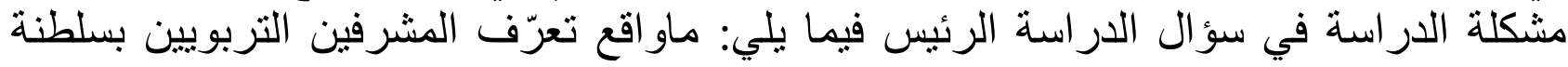

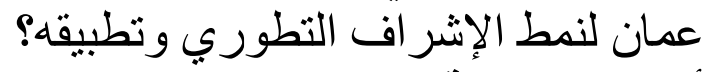

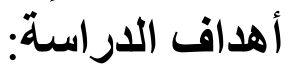

أ. تشخيص مدى معرفة المشرفين التربويين بسلطنة عمان لنمط الإشر اف التطوري؟

ب. كبف يطبق المشرفون التربويين بسلطنة عمان لنمط الإشر اف التطوري؟

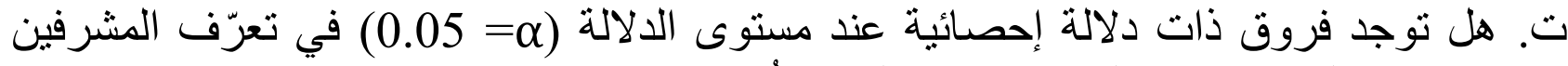

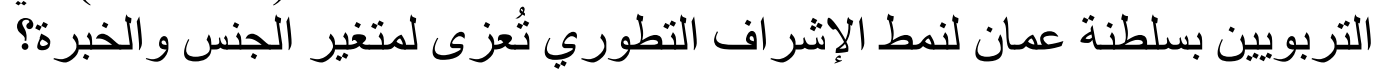

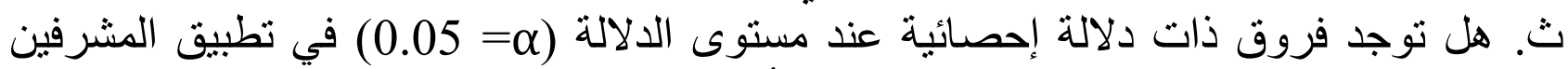

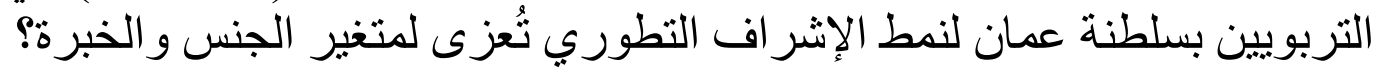
الإطار النظري والدر اسات السابقة:

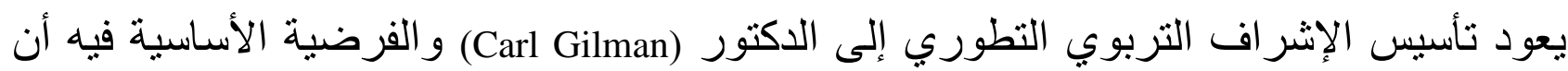

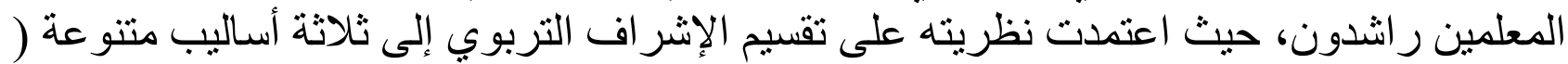

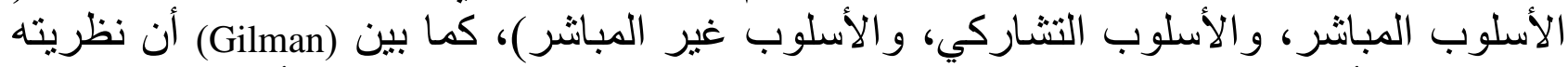

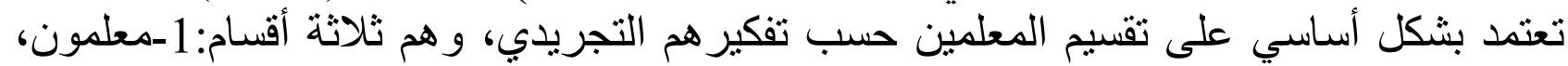

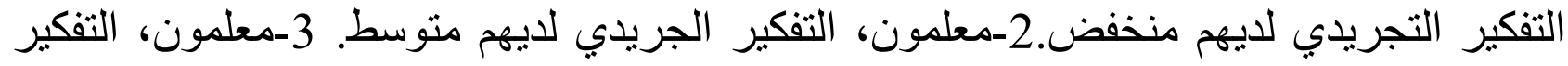
التجريدي لايهم مرتفع.

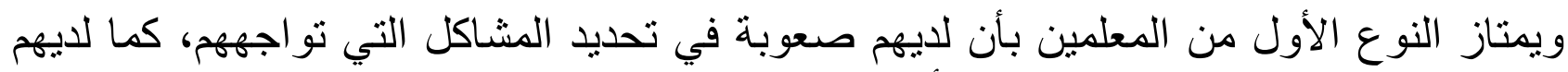

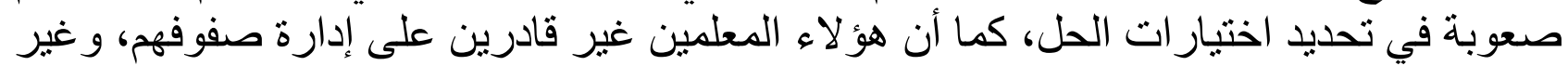

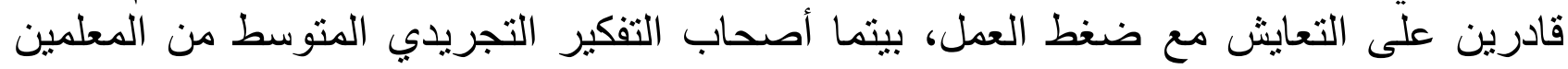

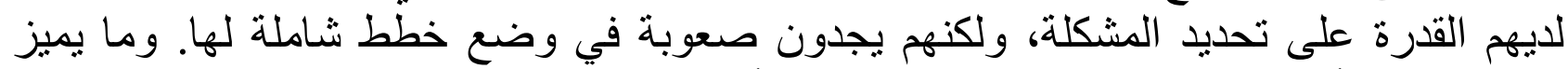

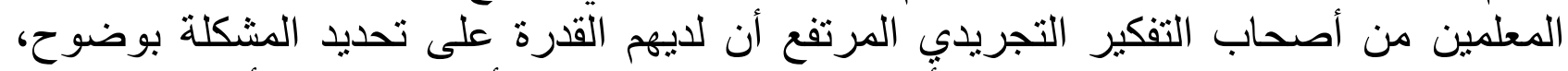

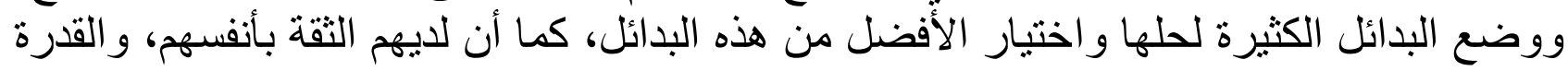

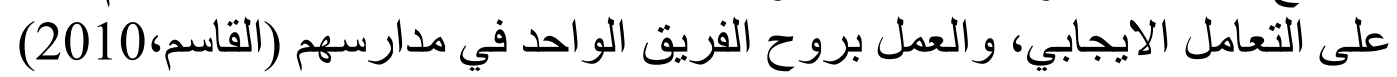
ويقسم (جلكمان) أساليب الإشر اف التطوري على النحو الآتي (القاسم،2010): - الأسلوب المباشر: يستخدم هذا الأسلوب لأصحاب التفكير التجريدي المنخفض من المعلمين،

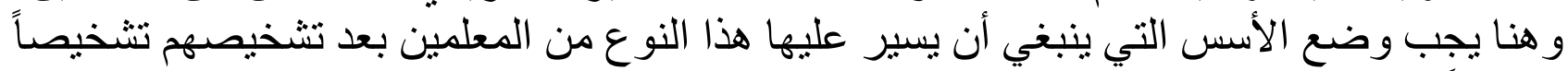
و اضحماً.

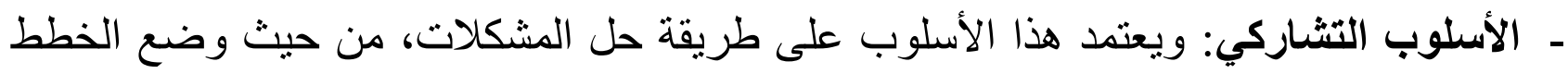

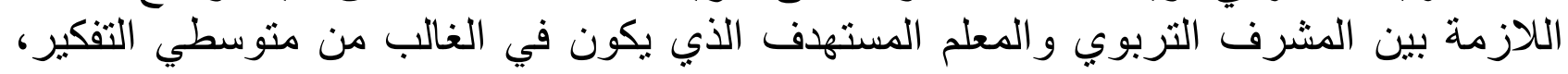
ومتوسطي الدافعية. - الأسلوب غير المباشر : يفترض هذا الأسلوب أن العملية التعليمية تقوم بالأصل على الخبرات 
الذاتية للمعلمين، و عليه التوصل لحل مشكلاته مع طلابه بنفسه، ويمتاز هؤلاء المعلمون بقدرات

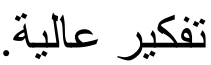

ويدافع (جلكمان) عن نظريته في الإشراف التربوي التطوري كونه ير اعي الفروق الفردية لدى

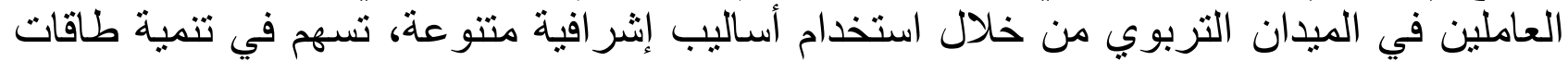

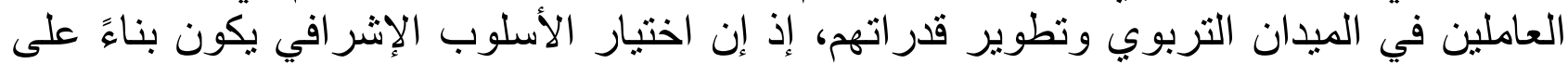

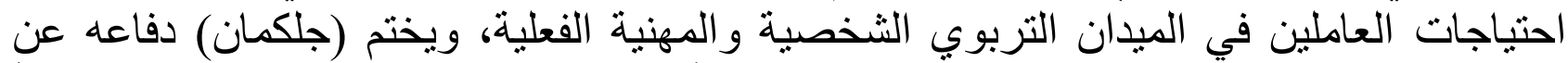

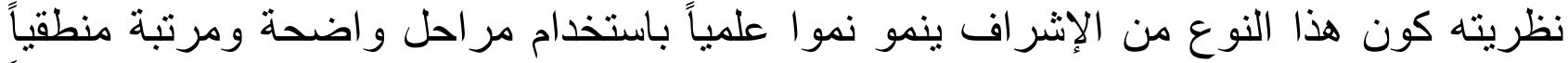

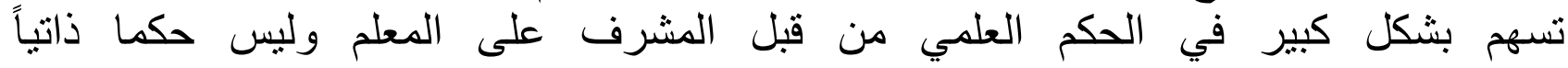
(الهمز اني، (2009).

ويمر تطبيق الإشراف التربوي التطوري من خلال ثناث مراحل رئيسة هي كما أشنار إليها، عطاري(2008) و البابطين (2005):

أ. التشخيص: حيث يقوم المشرف التربوي بعملية تشخيص لمستوى المعلم بشكل دقيق، لتحديد

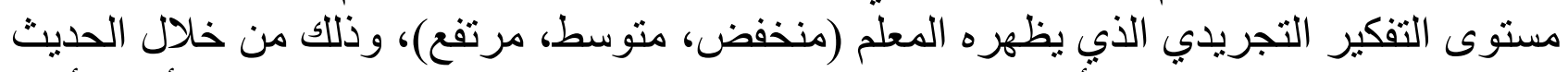

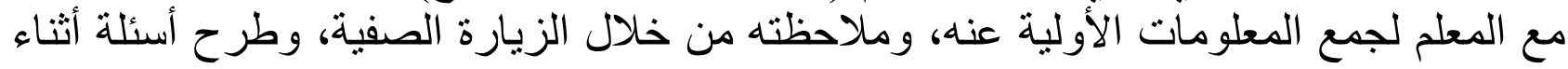
المداو لات الإشر افية، كما يستخدم بعض الأية المقاييس المطبقة لقياس التفكير.

ب. التطبيق: يتم فيها اختيار الأسلوب الإشر افي المناسب لمستوى التفكير التجريدي لدى المعلم،

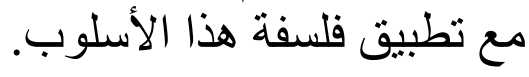

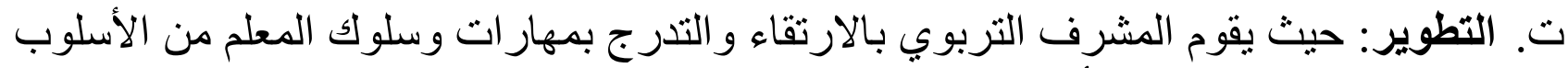

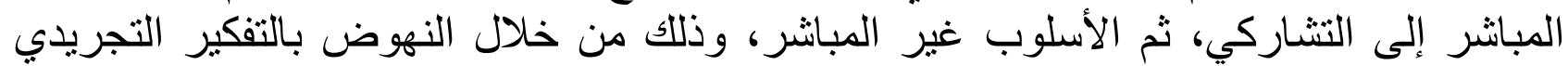

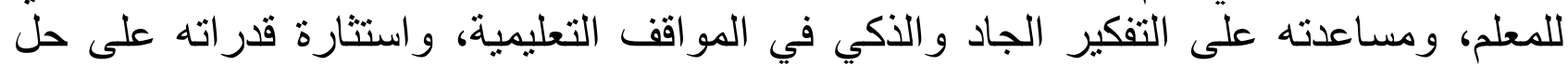
المشكلات، و التعامل مع القضايا التربوية داخل الصفير الصف وخارجه.

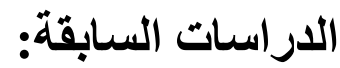

دراسة الرشيدي(2010): إلى تقييم الإشراف التطورئة من وجهة نظر المعلمين في منطقة حائل

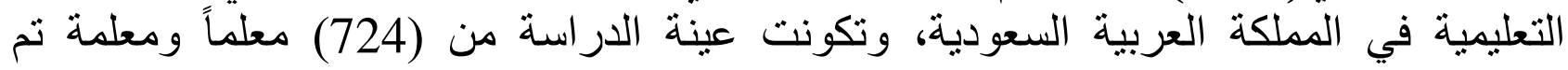

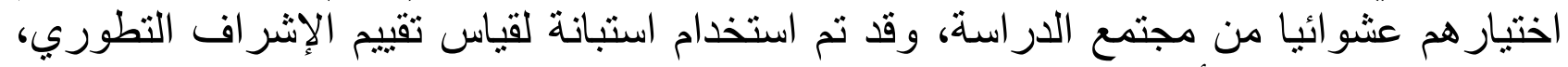

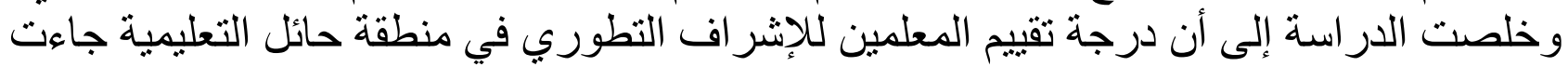

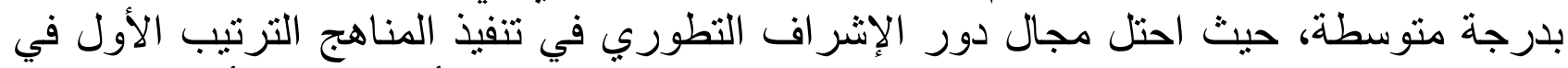

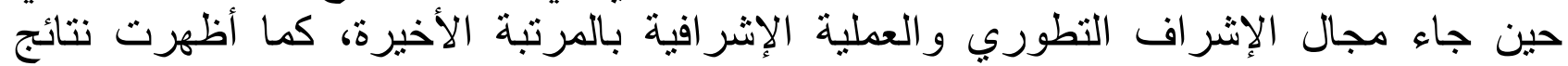

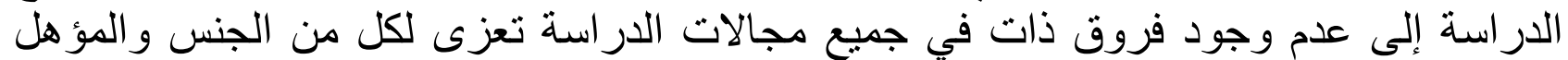
و الخبرة و التفاعل بينها، ووجود فرود فروق ذات ذات دلالة إحصائية في تقييم المعلمين للإشر اف التئ التربوي تعزى إلى الخبرة.

وتناول اللوح (2012): في دراسته درجة تحسين الإشراف التربوي التطوري للممارسات

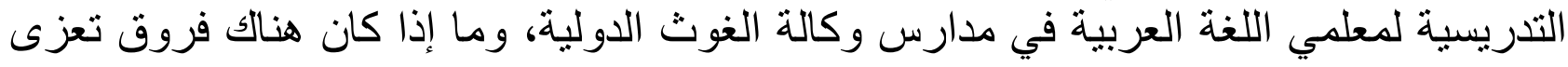




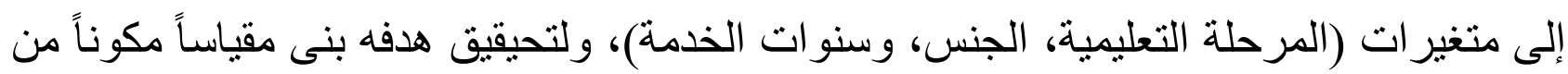

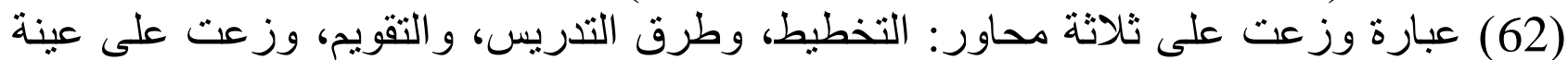

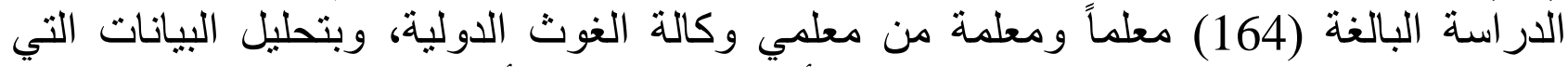

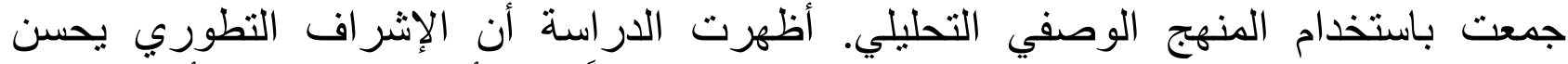

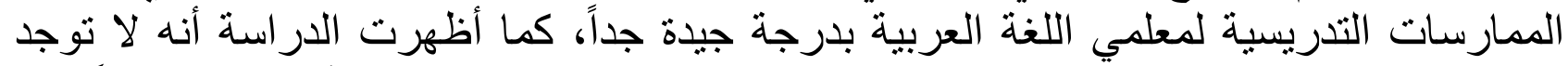

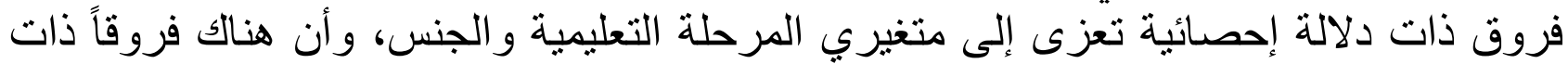
دلالة إحصائية تعزى إلى منغير سنو ات الخدمة إحسة.

هدفت دراسة البابطين (2014): إلى التعرف على درجة ممارسة المشرفين التربويين لأساليب الإشر اف التربوي التطوري من وجهة نظر المشرفين التربويين ومعلمي المدارس الثانوية بمدينة الرياض، وكذلك التعرف على درجة اختلاف آراء أفر اد الدراسة في درجة ممارسة المشرفين فئن التربوين لأسـاليب الإشراف التشافئ التطوري باختلاف متغيرات الدراسة ( العمل الحالي، المؤهل

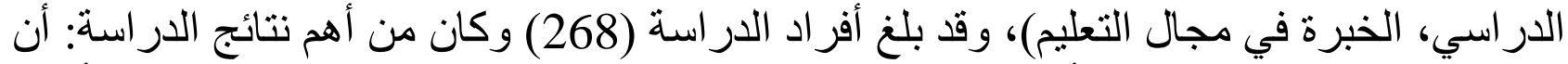

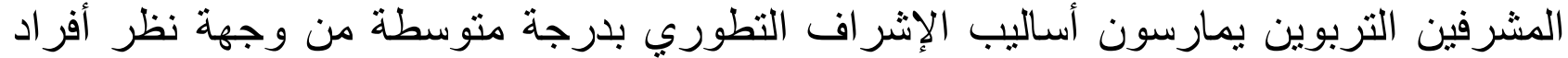

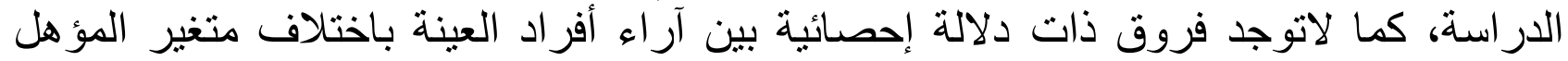
الدراسي، وتوجد فروق ذات دلالة إحصائية باختلاف متغيري العمل الحالي و الخبرة في مجال التعليم.

سعى الكلباني (2016): في در استه للتعرف على مدى ممارسة المشرفين التربويين لبعض أنماط

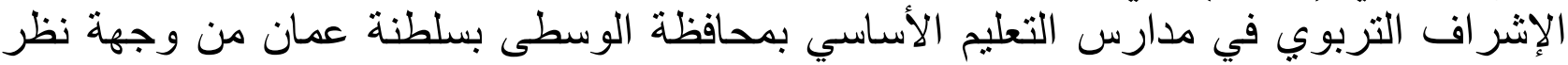

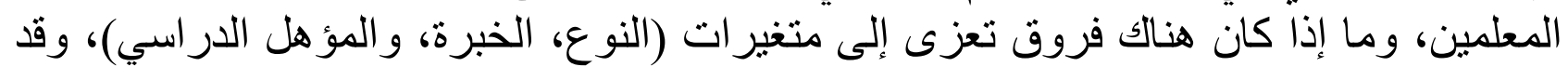
استخدم الباحث المنهج الوصفي، وتوصلت الدراسة لعدة نتائج منها أن ممارسة المشرفين

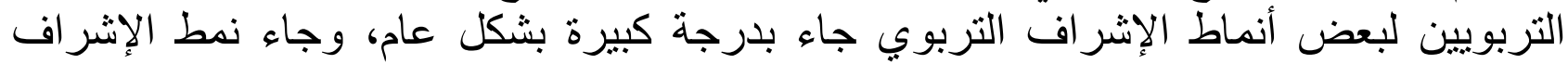

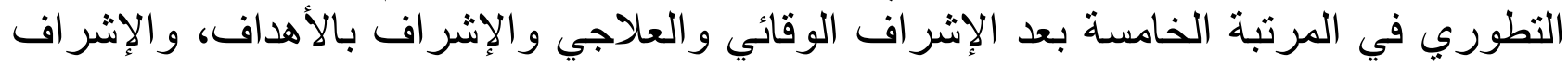

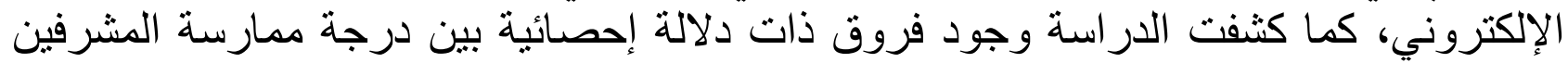

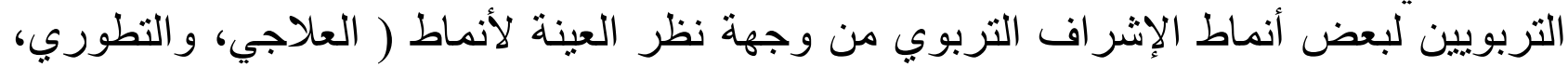

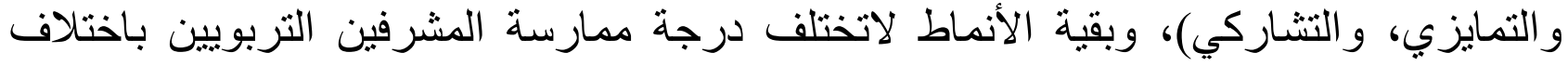

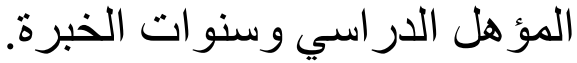

هدفت دراسة مدوالي وموذروفري Mudawali \& Mud-zofri (2017): إلى معرفة العلاقة بين الإشر اف التربوي التطوري والتطور المهني لدى المعلمين، وتكونت عينة الدراسة من من (256) معلماً ومعلمة في مدارس (حكومية وخاصة) تابعة لبلدية (لوكسيوماو) بأندونيسيا، و أظهري

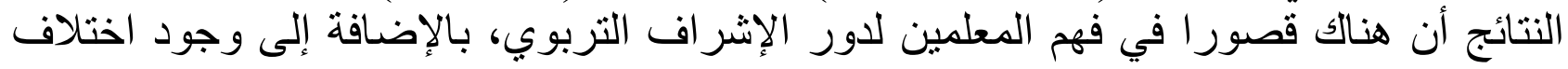
بين نظرة المعلمين للإشر اف التربوي وني والإشر اف التربوي المطبق.

وأجرى شلش(2018): دراسة هدفت إلى معرفة دور الإشراف التربوي التطوري في تحسين

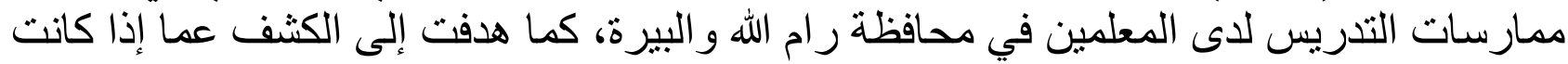
هنالك فروق في استجابات المبحوثين تعزى إلى متغيرات ( الجنس، الخبرة، التخصص)، ونهات ونكونت عينة الدر اسة من (124) معلما ومعلمة بنسبة (50\%) من مجتمع الدر اسة، وقد دلت نتائج الدر اسة 
أن الإشر اف التطوري له دور كبير في تحسين مدارسات التدريس عند المعلمين، كما بينت وجود فروق ذات دلالة إحصائية بالنسبة لمتغير الجنس ولصالح الذكور، و وعدم وجود فروق بالنسبة لمتغبري الخبرة و التخصص.

\section{منهج الدراسة:}

اعتمدت الدراسة المنهج الوصفي (المسحي)، لملاعمة هذا المنهج لطبيعة الدراسة الحالية وتحقيق

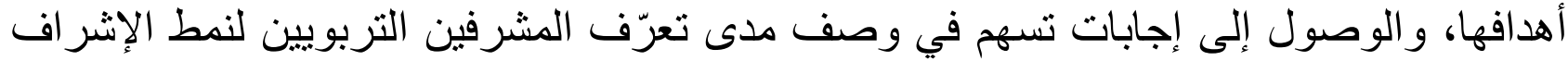
التطوري في سلطنة عمان ومدى تطبيقهم، و التحليل و المقارنة بين النتائج المتحصلة في الفروقات فئن الإحصائية ذات الدي سلالة الإحصائية.

مجتمع الدراسة: تكون مجتمع الدراسة من جميع المشرفين التربوبين بالمديريات التعليمية بوزارة

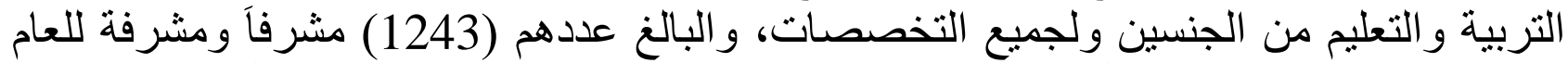

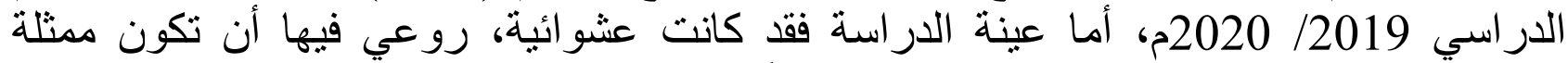
لخصائص المجتمع، وقد بلغ حجمها (285) مشرفاً ومشرفة، من جميع المديريات التعليمية.

أداة الدراسة: - مارة

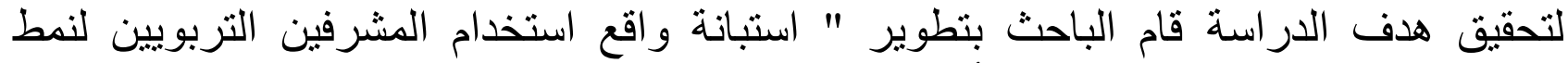

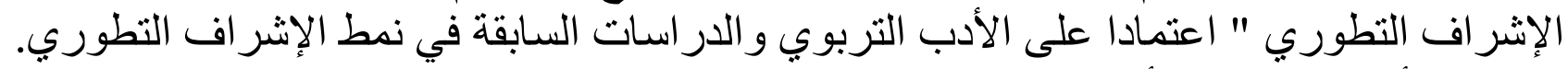
تكونت الأداة بصيختها الأولية من (19) فقرة موزعة على على محورين، وقد تم استخر اج دلالات الصدق و الثبات لأداة الدر اسة على الأهى النحو الآتي:

\section{أولاً: صدق الأداة}

تم التحقق من الصدق الظاهري للاستبانة، وصدق المحتوى من خلال عرضها على (10) محكما

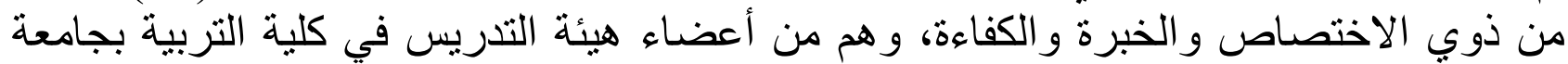

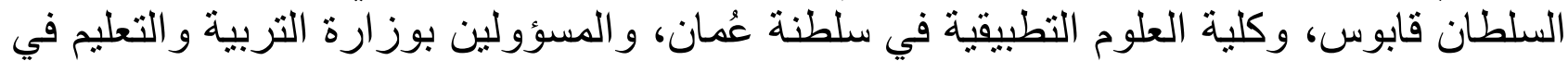
سلطنة عُمان من مشرفي عموم ومشرفين أوائل ومشرفين تربويين، وبناء على ملى ملاحظات المحكمين تم تعديل (10) فقرات وزيادة فقرنين، وبلغ عدد فقرات الأداة بعد هذه المرحلة (21) فقرة قسمت إلى محورين رئيسين: أولهما " الجانب المعرفي" ونكون من (9) فقرات، أما المحور الآخر فكان " الجانب التطبيقي" وتكون من (12) فقرة. حيث تم اعتماد سلم (ليكرت) الخماسي لتصحيح أدوات الدر اسة، بإعطاء كل فقرة من فقر اته درجة و احدة من بين درجاته الخمس (موافق فون

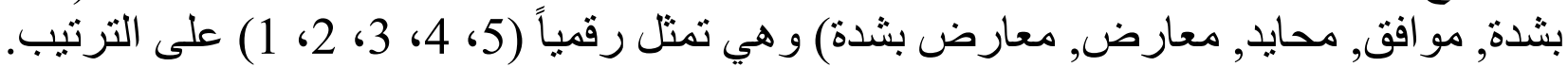

كما تم التأكد من صدق البناء للمقياس، حيث استخرجت معاملات ارتباط فقرات كل محور مع

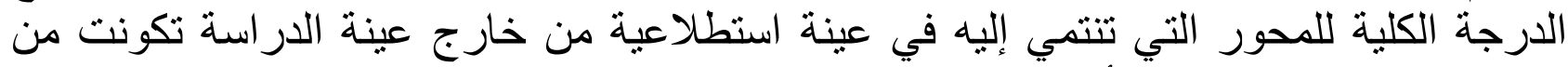
(30) مشرف تربوي، حيث أن معامل الارتباط هنا يمثل دلالة للصدق بالنسبة لكل فقرة في صورة

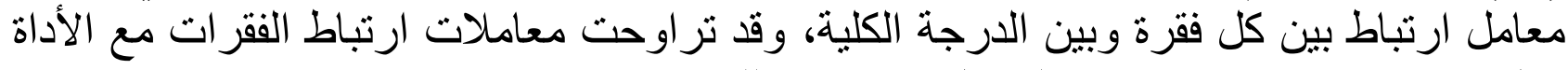

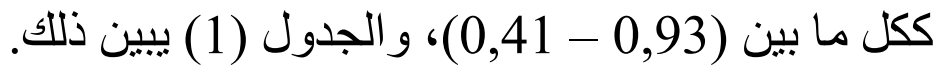




\begin{tabular}{|c|c|c|c|}
\hline \multicolumn{2}{|c|}{ التطبيق } & \multicolumn{2}{|c|}{ التعرف } \\
\hline مع الأرنباط & رقم الفقرة & مع الأنباط & رقم الفقرة \\
\hline $.56(* *)$ & $\overline{10}$ & $.93(* *)$ & 1 \\
\hline $.41(* *)$ & 11 & $.93(* *)$ & 2 \\
\hline $.57(* *)$ & 12 & $.92(* *)$ & 3 \\
\hline $.64(* *)$ & 13 & $.88(* *)$ & 4 \\
\hline $.77(* *)$ & 14 & $.90(* *)$ & 5 \\
\hline $.54(* *)$ & 15 & $.71(* *)$ & 6 \\
\hline $.72(* *)$ & 16 & $.87(* *)$ & 7 \\
\hline $.71(* *)$ & 17 & $.51(* *)$ & 8 \\
\hline $.70(* *)$ & 18 & $.86(* *)$ & 9 \\
\hline $.73(* *)$ & 19 & & \\
\hline $.71(* *)$ & 20 & & \\
\hline $.66(* *)$ & 21 & & \\
\hline
\end{tabular}

*دالة إحصائيا عند مستوى الدلالة (0.05). **دالة إحصائيا عند مستوى الدلالة (0.01). وتجدر الإشارة أن جميع معاملات الارتباط كانت ذات درجات مقبولة ودالة إحصائيا، ولذلك لم يتم حذف أبي من هذه الفقرات. ثانياً: اثبات أداة الدراسة

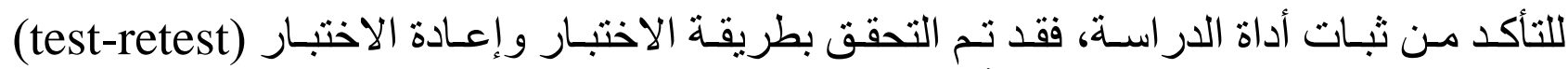

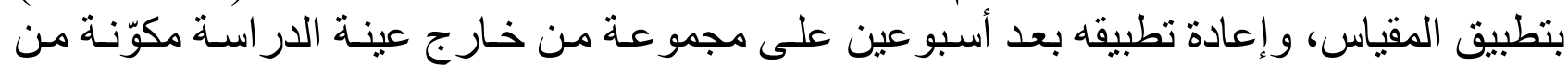

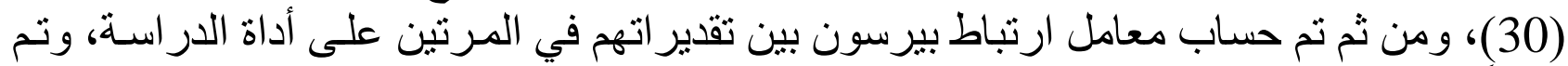

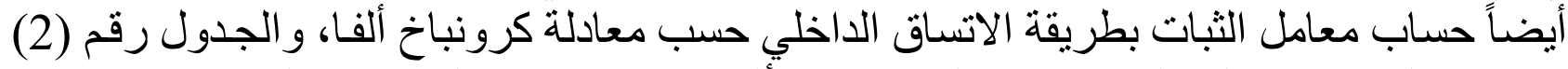

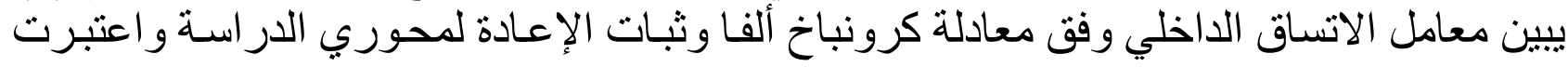
هذه القيم ملائمة لغايات هذه الأن الدار استة.

جدول (2) معامل الاتساق الداخلي كرونباخ ألفاوثبات الإعادة للمجالات و الدرجة الكلية

\begin{tabular}{|c|c|c|}
\hline الاتساق الداخلي & ثبات الإعادة & المجال \\
\hline 0.94 & 0.90 & التعرف \\
\hline 0.85 & 0.92 & التطبيق \\
\hline
\end{tabular}

المعالجات الإحصائية: تم استخدام برنامج الحزم الإحصائية للعلوم الاجتماعية (SPSS) باستخدام التحليل الوصفي الإحصائي وكما يأتي: 
ـ - التحليل الوصفي الإحصائي، استخراج المتوسطات الحسابية والانحر افات المعيارية والنسب

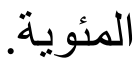
- معتبار تي (T-Test) لاختبار دلالة الفروق بين المشرفين.

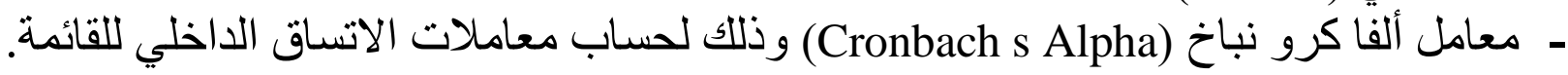

\section{نتائج الاراسة:}

\section{أولاً: النتائج المتعلقة بالسؤال الأول:}

ما واقع تعرّف المشرفين التربويين بسلطنة عمان لنمط الإشراف التطوري من وجهة نظر المشرفين أنفسهم؟ تصنج

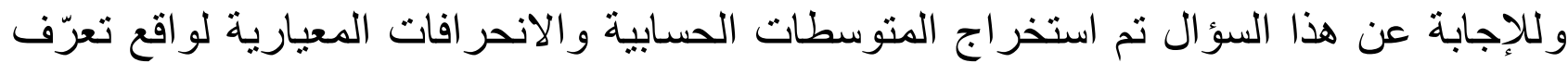
المشرفين التربويين بسلطنة عمان لنمط الإشر اف التشواف التطوري من وجهة نظر المشرفين أنفسهم، و الجدول أدناه يوضنح ذلك.

جدول (3) المتوسطات الحسايية و الانحر افات المعيارية لو اقع تعرّف المشرفين التربوبين بسلطنة

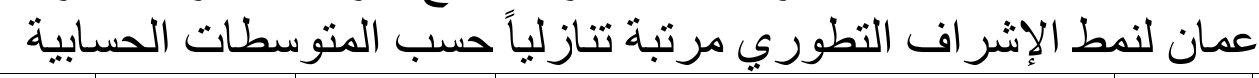

\begin{tabular}{|c|c|c|c|c|c|}
\hline المستوى & الالمعراف & الحسابي & الفقرة & الرقم & الرتبة \\
\hline متوسط & 1.203 & 3.59 & مهار أتي الإشر الإشر افة التطوري في صقل & 9 & 1 \\
\hline متوسط & .821 & 3.51 & بنظريات الذكاء و القدر الَّات العقلية. & 8 & 2 \\
\hline متوسط & 1.205 & 3.44 & أدرك أهمية نمط الإشر اف التشرية التربوي & 4 & 3 \\
\hline متوسط & 1.164 & 3.40 & تصفيق نمط الإشر آ أعرف التربوري في & 5 & 4 \\
\hline متوسط & 996 & 3.39 & لدنتويات التنفكير التجريدي التئيف المعين إلى & 6 & 5 \\
\hline متوسط & 1.215 & 3.32 & التطورف مصطلح الإشر اف التربوي & 1 & 6 \\
\hline متوسط & 1.205 & 3.20 & 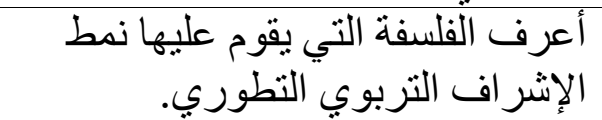 & 2 & 7 \\
\hline متوسط & 1.128 & 3.06 & نظريةّ الإشر قياف دافعية المعلمين وفق & 7 & 8 \\
\hline متوسط & 1.219 & 2.94 & 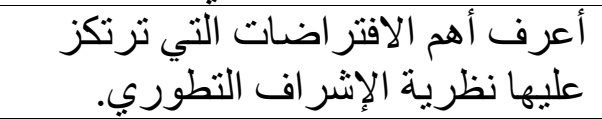 & 3 & 9 \\
\hline متوسط & .956 & 3.32 & التعرف ككل & & \\
\hline
\end{tabular}




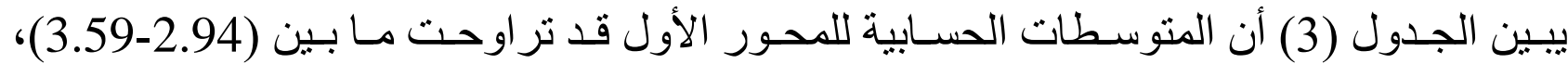

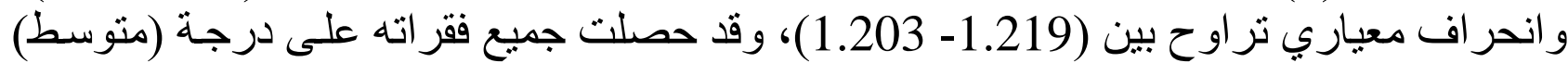

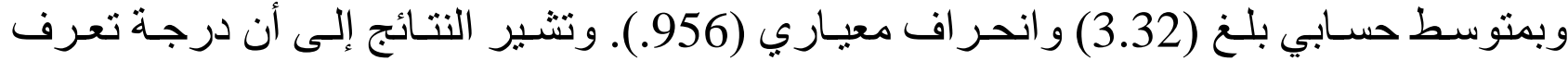

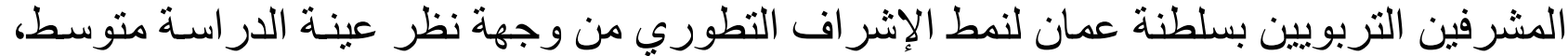

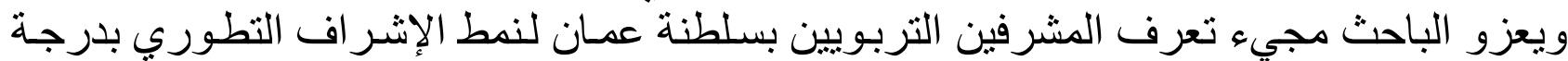

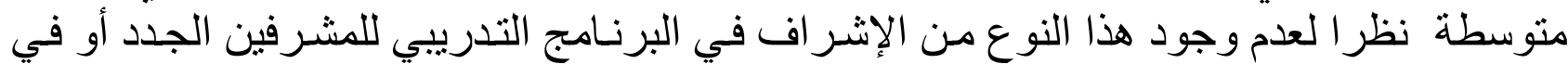

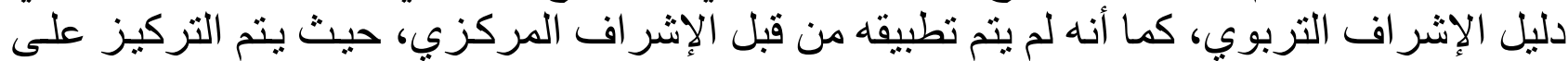

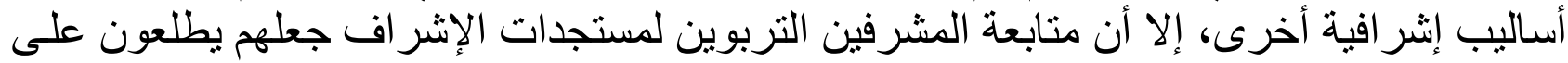

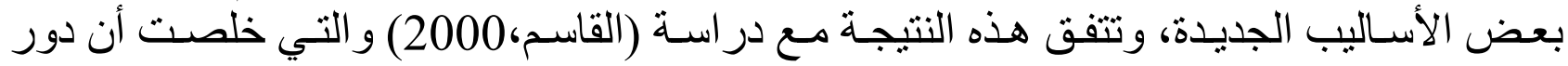

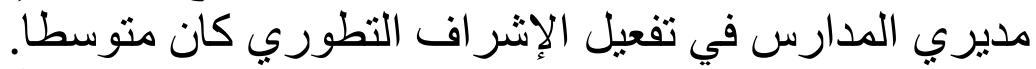

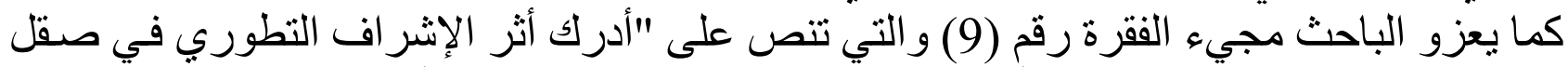

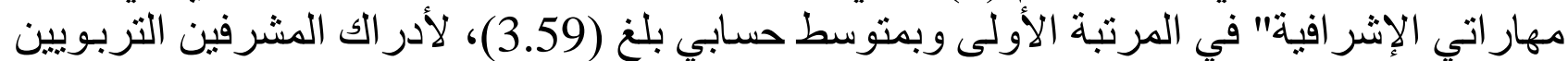

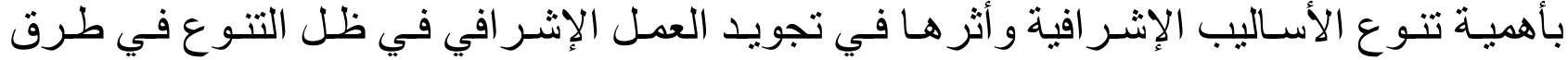

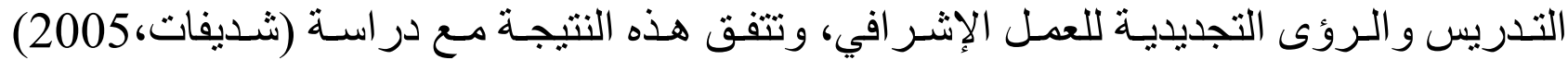

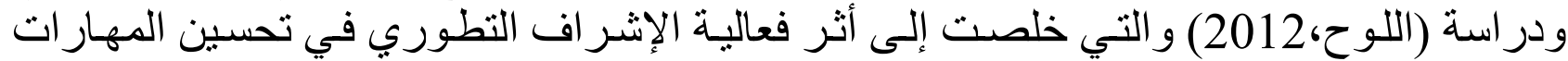

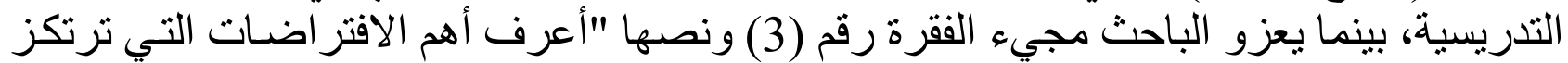

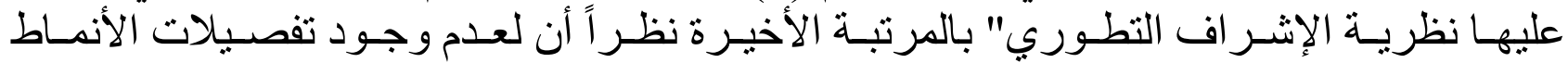

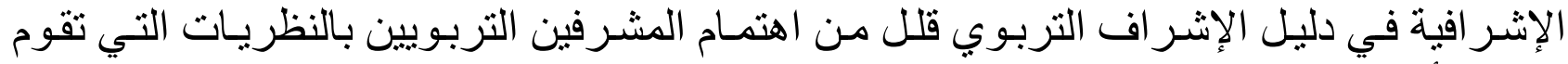
عليها الأنماط الإشر افية المتنو عة.

\section{ثانياً: النتائج المتعلقة بالسؤال الثاني:}

ما واقع تطبيق المشرفين التربويين بسلطنة عمان لنمط الإشر اف التطوري؟ للإجابة عن هذا السؤال تم استخر اج المتوسطات الحسابية والانحر افات المعيارية لو اقع تطبيق المشرفين التربويين بسلطنة عمان لنمط الإشر اف التطوري، التشئ والجدول أدناه يوضح ذللك.

جدول (4) المتوسطات الحسابية والانحر افات المعيارية لو اقع تطبيق المشرفين التربويين بسلطنة

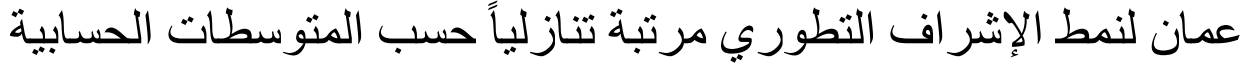

\begin{tabular}{|c|c|c|c|c|c|}
\hline المستوى & الانحر افياري & المتوسطي & الفقرة & الرقم & الرتبة \\
\hline مرتفع & .630 & 4.35 & الذين أثنرف الفروق عليهر. الفردية بين المعلمين & 12 & 1 \\
\hline مرتفع & .725 & 4.31 & 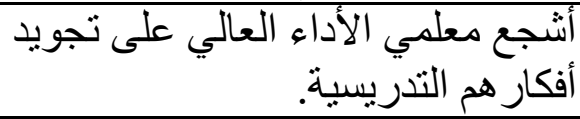 & 19 & 2 \\
\hline مرتفع & .746 & 4.20 & 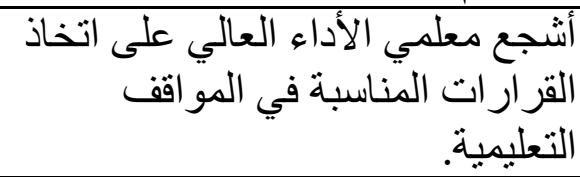 & 20 & 3 \\
\hline مرتفع & .653 & 4.18 & أحرض على تطوير أداء المعلمين بشئ مستمر. & 14 & 4 \\
\hline
\end{tabular}


IJASOS- International E-Journal of Advances in Social Sciences, Vol. VI, Issue 16, April 2020

\begin{tabular}{|c|c|c|c|c|c|}
\hline المستوى & الانحر افياري & الحستوسط & الفقرة & الرقم & الرثبة \\
\hline مرتفع & .872 & 4.16 & 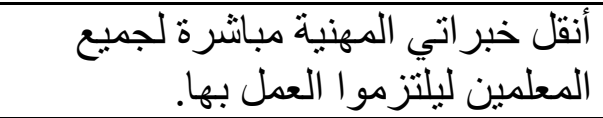 & 11 & 5 \\
\hline مرتفع & .599 & 4.12 & 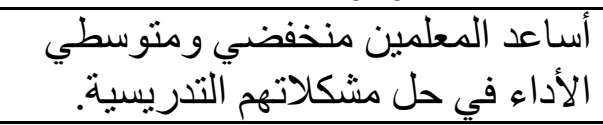 & 16 & 6 \\
\hline مرتفع & .821 & 4.09 & 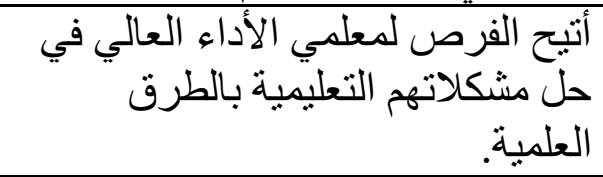 & 21 & 7 \\
\hline مرتفع & .923 & 4.00 & ألعطي التوجيهات المباثرة منخفي و المستمرة & 10 & 8 \\
\hline مرتفع & .709 & 3.97 & أختبار الط المعلمين متوسطي الأداء في أدني & 17 & 9 \\
\hline مرتفع & .669 & 3.92 & أرأثابع مدى على مهارة معينها في زيار اتئ المعلم & 13 & 10 \\
\hline مرتفع & .623 & 3.87 & وأرصند مستوى تقدم معلمي منخفضي الأداء في حل مشكلتهم & 18 & 11 \\
\hline متوسط & .950 & 3.40 & أطبق الأسلوب التشـاركي في زيار اتي & 15 & 12 \\
\hline مرتفع & .471 & 4.05 & التطبيق & & \\
\hline
\end{tabular}

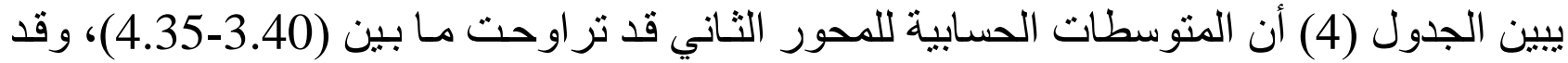

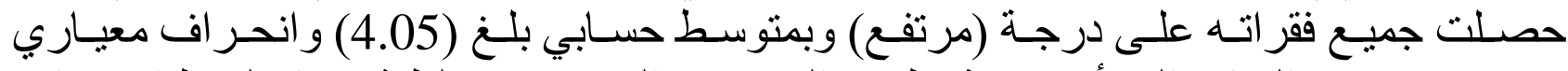

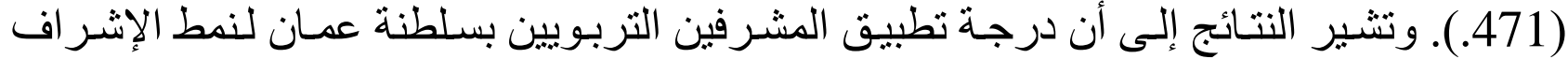

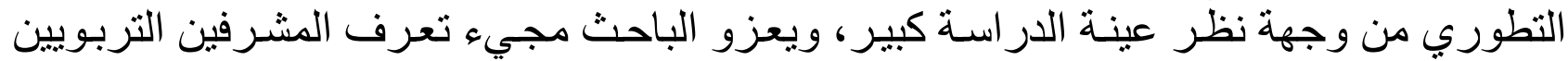

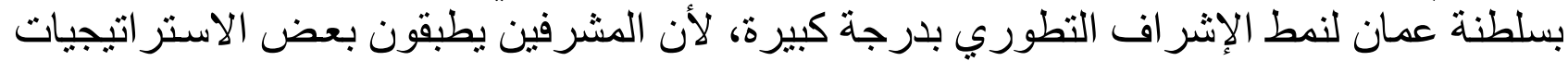

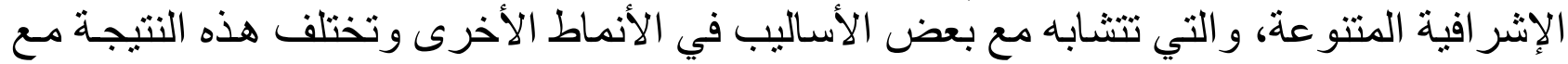

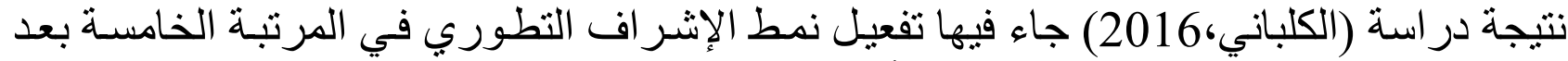

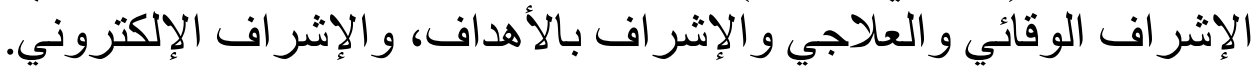

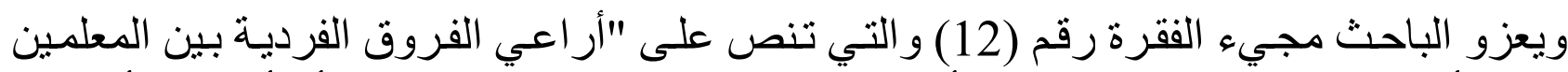

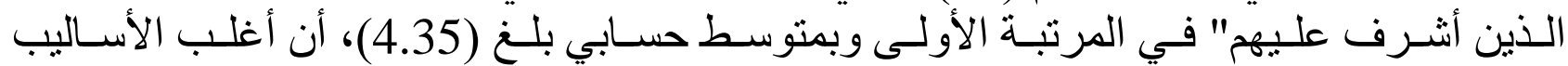

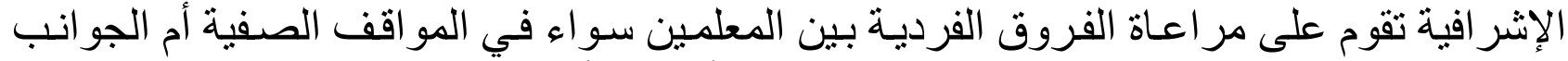

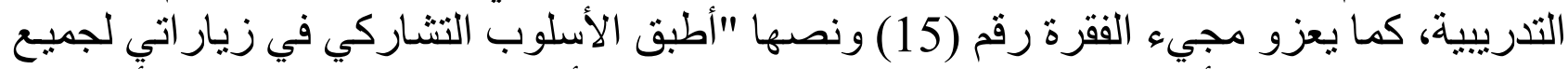

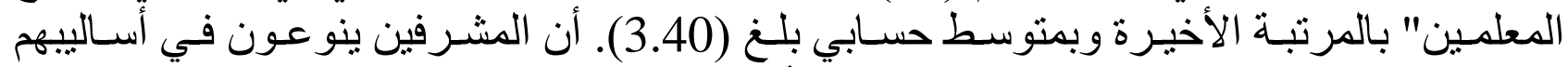
الإشر افية باستمر ار وبالتالي يقل الاعتماد على الأسلى الألوب التشاركي. 
هـل توجد فـروق ذات دلالـة إحصـائية عنـد مسـتوى الدلالـة (م = 0.05) في تعـرّف المشـرفين التربوبين بسلطنة عمان لنمط الإشر اف التطوري تُعزى لمتغيري الجنس، و والخبرة؟

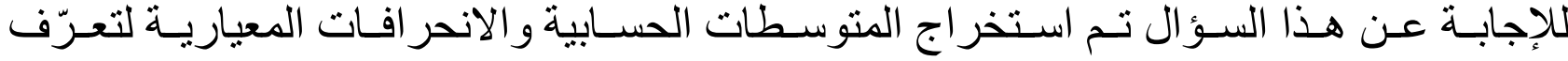
المشـرفين التربـويين بسـلطنة عمـان لـمط الإشـر اف التطـوري حسـبـ متغيـري الجنس، و الخبـرة و الجدول أدناه يبين ذلك.

جدول رقم (5) المتوسطات الحسابية والانحر افات المعيارية لتعرّف المشرفين التربوبين بسلطنة عمان لنمط الإشر اف التطوري حسب متغير ات الجنس، و الخبرة

\begin{tabular}{|c|c|c|c|c|}
\hline العدد الع & الانحرياري & المتوسط الحسابي & الخبرة & الجنس \\
\hline 33 & 1.075 & 2.77 & 10 سنو ات فما دون & ذكر \\
\hline 79 & .973 & 3.25 & 15-11 سنة & \\
\hline 85 & .954 & 3.57 & اكثر من 15سنوات & \\
\hline 197 & 1.018 & 3.31 & المجموع & \\
\hline 18 & .775 & 3.27 & 10 سنوات فما دون & أنثى \\
\hline 25 & .868 & 3.24 & 15-11 سنة & \\
\hline 45 & .794 & 3.42 & اكثر من 15سنوات & \\
\hline 88 & .807 & 3.34 & المجموع & \\
\hline 51 & 1.001 & 2.95 & 10 سنو ات فما دون & المجموع \\
\hline 104 & .945 & 3.25 & 15-11 سنة & \\
\hline 130 & .901 & 3.52 & اكثر من 15سنوات & \\
\hline 285 & .956 & 3.32 & المجموع & \\
\hline
\end{tabular}

يبين الجدول (5) تبايناً ظاهرياً في المتوسطات الحسابية و الانحر افات المعيارية لتعرّف المشرفين التربوبين بسلطنة عمان لنمط الإشر اف التطوري بسبب اختافلاف فئات متغيرات الجنس الجس، و الخبرة ولبيان دلالة الفروق الإحصائية بين المتوسطات الحسابية تم استخدام تحليل التباين الثنائي جدول

جدول رقم (6) تحليل التباين الثنائي لأثر الجنس، و الخبرة على تعرّف المشرفين التربويين بسلطنة عمان لنمط الإشر اف التطوري

\begin{tabular}{|c|c|c|c|c|c|}
\hline الإحصائية & قيمة ف & متوسط المربعات & الحرية & المربعاث & مصدر التباين \\
\hline .866 & .029 & .025 & 1 & .025 & الجنس \\
\hline \multirow[t]{3}{*}{.001} & 7.328 & 6.436 & 2 & 12.872 & سنو ات الخبرة \\
\hline & & .878 & 281 & 246.771 & الخطأ \\
\hline & & & 284 & 259.701 & الكلي \\
\hline
\end{tabular}

يتبين من الجدول (6) الآتي: 


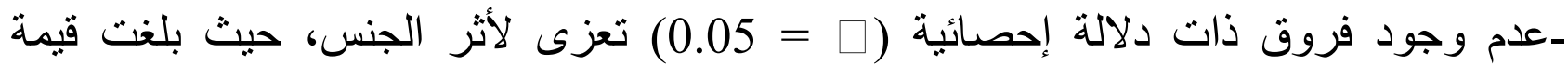

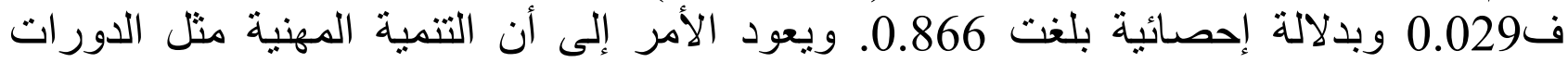
و الورش التدريبية يشارك فيها الجميع بغض النظر عن الجنس.

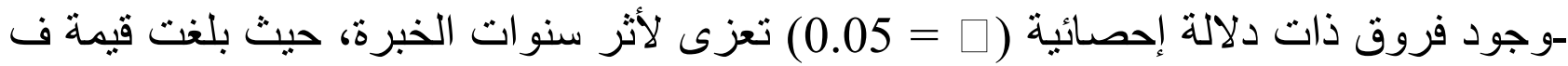

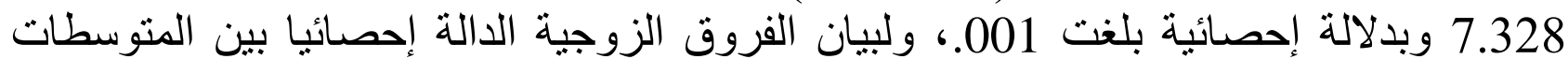

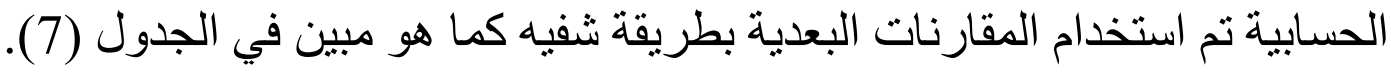
جدول (7) المقارنات البعدية بطريقة شفية لأثر سنوات الخبرة على تعرّف المشرفين التربويين بسلطنة عمان لنمط الإشر اف التطوري لنفي

\begin{tabular}{|c|c|c|c|c|}
\hline سنو اتر من 15 & سنة & سنوات & الحستوسط & \\
\hline & & & 2.95 & 10-10 سنو ات \\
\hline & & .30 & 3.25 & 15-11 سنة \\
\hline & .27 & $* .57$ & 3.52 & اكثر من 15 سنوات \\
\hline
\end{tabular}

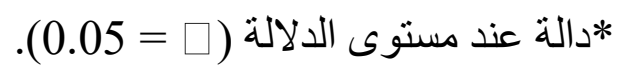

يتبين من الجدول (7) وجود فروق ذات دلالة إحصائية (ص =

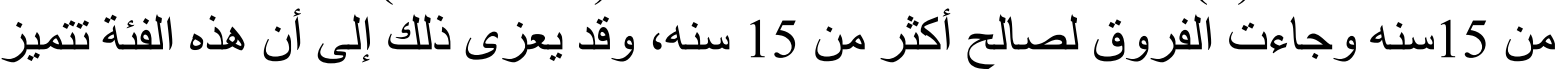

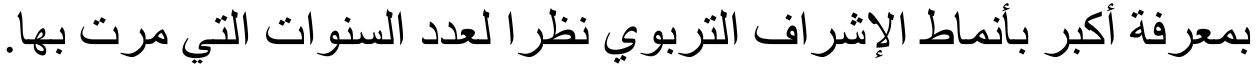

رابعاً: النتائج المتعلقة بالسؤال الرابع:

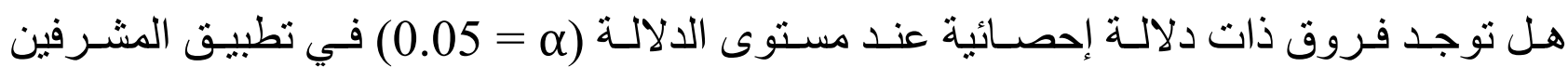

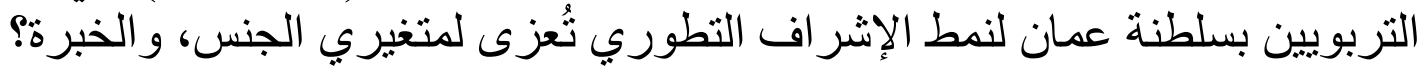

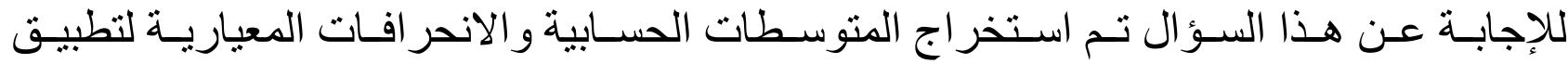

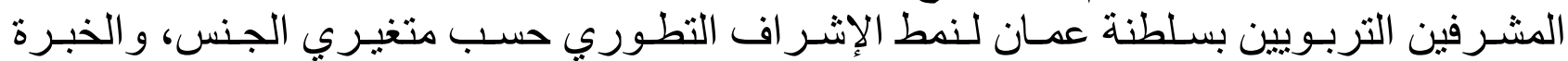
و الجدول أدناه بيين ذلك.

جدول رقم (8) المتوسطات الحسابية و الانحر افات المعيارية لتطبيق المشرفين التربو يين بسلطنة

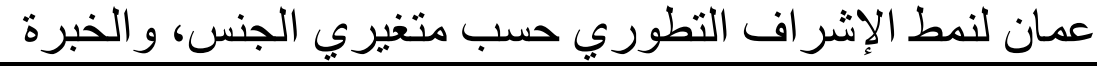

\begin{tabular}{|c|c|c|c|c|}
\hline العدد & الالانحريافي & المتوسط الحسابي & الخبرة & الجنس \\
\hline 33 & .348 & 3.71 & 10-10 سنو ات & ذكر \\
\hline 79 & .457 & 3.97 & 15-11 سنة & \\
\hline 85 & .502 & 4.09 & اكثر من 15سنوات & \\
\hline 197 & .478 & 3.98 & المجموع & \\
\hline 18 & .301 & 4.31 & 10-10سنوات & انثى \\
\hline 25 & 401 & 4.21 & $11-15$ & \\
\hline
\end{tabular}




\begin{tabular}{|c|c|c|c|}
\hline 45 & .464 & 4.16 & اكثر من 15سنوات \\
\hline 88 & .417 & 4.20 & المجموع \\
\hline 51 & .437 & 3.92 & 10-10سو ات \\
\hline 104 & .454 & 4.03 & $11-15$ \\
\hline 130 & .488 & 4.11 & اكثر من 15سنوات \\
\hline 285 & .471 & 4.05 & المجموع \\
\hline
\end{tabular}

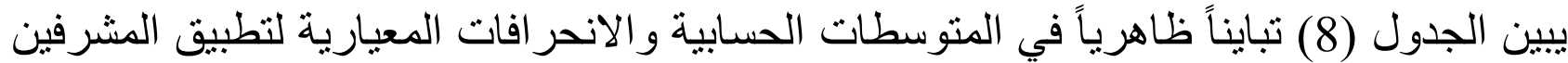

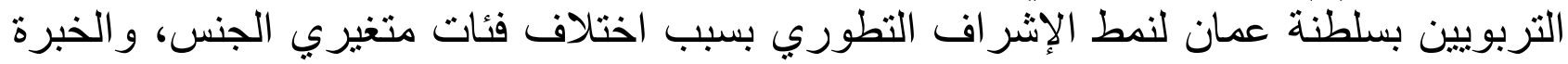
ولبيان دلالة الفروق الإحصائية بين المتوسطات الحسابية تم استخدام تحليل التباين الثنائي جدول

جدول رقم (9) تحليل التباين الثنائي لأثر الجنس، والخبرة على تطبيق المشرفين التربويين بسلطنة عمان لنمط الإشر اف الف التطوري

\begin{tabular}{|c|c|c|c|c|c|}
\hline الإحصائية & قيمة ف & المربعات & الرجرية & المجبعوات & مصدر التباين \\
\hline .000 & 14.218 & 2.963 & 1 & 2.963 & الجنس \\
\hline \multirow[t]{3}{*}{.036} & 3.354 & .699 & 2 & 1.398 & سنوات الخبرة \\
\hline & & .208 & 281 & 58.568 & الخطأ \\
\hline & & & 284 & 62.973 & الكلى - الك \\
\hline
\end{tabular}

يتبين من الجدول (9) الآتي:

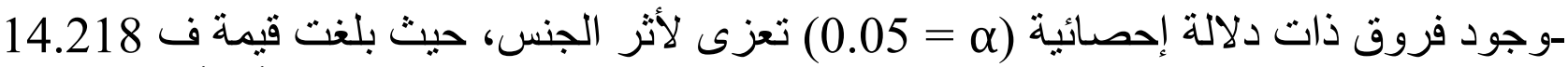

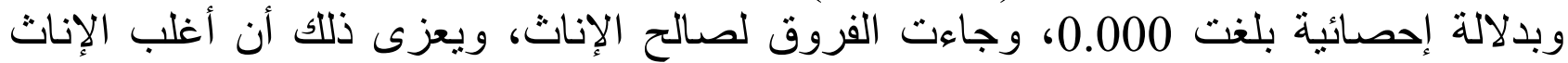
يحرصن على تطبيق أساليب إثر افية متنو عة وجديدة الفيدة أكثر بعكس الذكور .

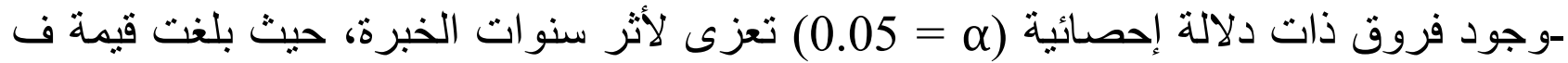

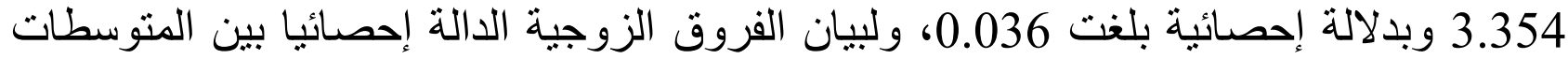

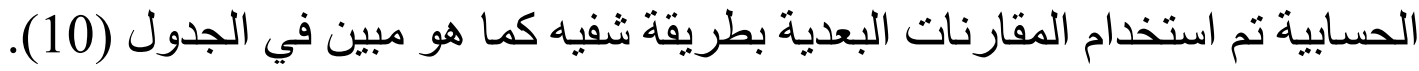

جدول (10) المقارنات البعدية بطريقة شفية لأثر سنوات الخبرة على تطبيق المشرفين التربويين بسلطنة عمان لنمط الإشر اف التشوات التطوري

\begin{tabular}{|c|c|c|c|c|}
\hline سثر من 15 & 15-11 سنة & 10-1 سنوات & الحستوسطي & السنوات \\
\hline & & & 3.92 & 10-10 سنوات \\
\hline & & .11 & 4.03 & 15-11 سنة \\
\hline & .09 & $* .19$ & 4.11 & اكثر من 15سنوات \\
\hline
\end{tabular}

(دالة عند مستوى الدلالة (م = 0.05). يتبين من الجدول (11) وجود فروق ذات دلالة إحصائية (م = 0.05) بين 1-10 سنوات و أكثر 
من 15سنوات وجاءت الفروق لصالح أكثر من 15 سنة، ويعزى ذلك أن الخبرة لها دور كبير في

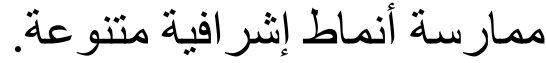

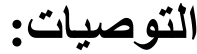

في ضوء النتائج التي توصلت إليها الدر اسة، يوصي الباحث بالآتي:

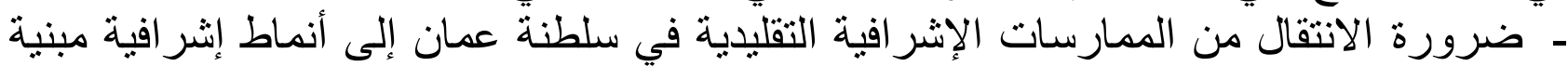

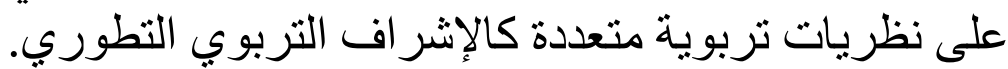

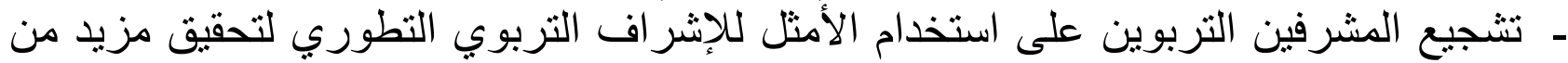
أبو عابد، محمود. (2004). الدرجع في الإثراف والعملية الإشر/فية، دار الكتاب الثقافي، الأردن. القاسم، منصور. (2010). دور مديري الددارس في تفعيل الإشراف التطوري بالهدارس الحكومية في محافظة جدة، رسالة ماجستير غير منشور ، كلية التربية - جامعة أم القرى.

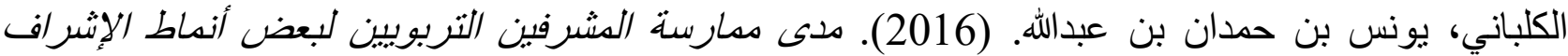

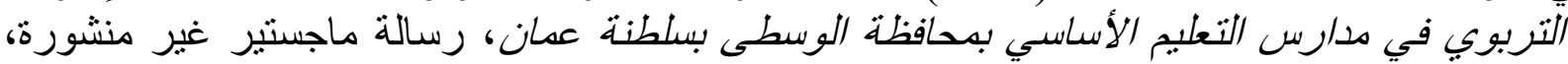
جامعة نزوى، سلطنة عمان.

الدروشي، خميس بن سعيد بن خميس. (2016). درجة مدارسة الدشرفين التربوبين الأوائل أدوارهم الوظيفية بححافظة جنوب الثرقية في سلطنة عمان، رسالة ماجستير غير منشورة، جامعة نزوى، سلطنة عمان. البابطين، عبدالعزيز. (2005). اتجاهات حديثة في الإشر/ف التربوي، مكتبة العبيكان، الرياض. التوبي، عيسى. (2005). الكفايات الأدائية اللازمة للمشرفين التربوبين في سلطنة عدان وددى تدكنهم منها،

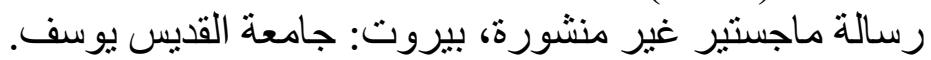

الحسني، يحي بن سعيد. (1999). الاحتياجات التدريبية للمشرفين التربوبين كما براها المشرفون والمعلدون في

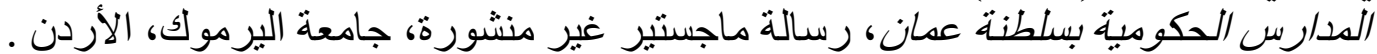

الخياري، ناصر بن راشد. (2002). مدى مدارسة موجه الدراسات الاجتماعية لمهامه الفنية من وجهة نظر

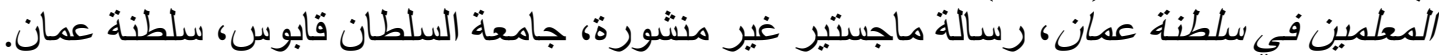

الزهيري، حيدر عبدالكريم. (2017). مناهج البحث التربوي، مركز ديينو لتعليم التفكير - الطبعة1، الأردن. الرشيدي، إبر اهيم عبدالله. (2010). تقبيم الإثراف التطوري من وجهة نظر الدعمين في منطقة حائل التعليمية في المدلكة العربية السعودية، جامعة مؤنة، بحث ماجستير غير منشور.

شاهين، عبدالرحمن يوسف. (2010). فاعلية تطبيق الإثراف التربوي التطوبيري التثاركي في تحسين التربين

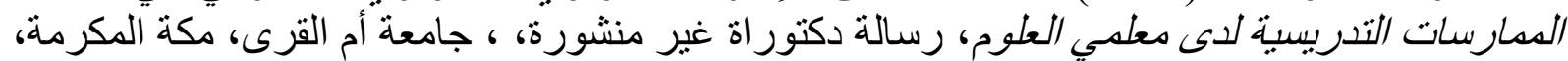
المملكة العربية السعودية النية 
شلش، باسم وحرز الله، حسام. (2017). الإشر اف التربوي وعلاقته في التطور المهني لدعلدي الرياضيات. عطاري، عارف. (2005). الإثراف التربوي ونماذجه النظرية والتطبيقبة العدلية، مكتبة الفلاح، الكويت.

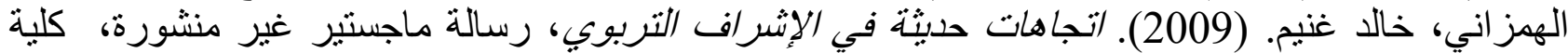
التربية، جامعة الملك سعود.

اليحمدي، حمد بن هلال. (2005). مدى فاعلبة أسالبي الإشراف المطبقة في سلطنة عمان من وجهة نظر

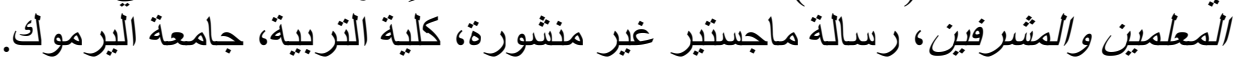

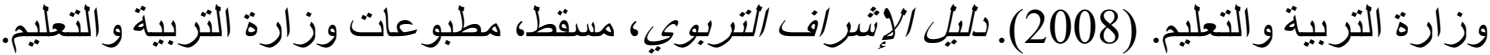

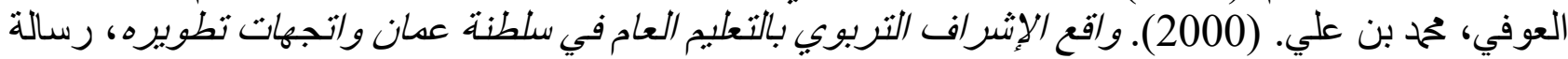
ماجستير غير منشورة، كلية التربية، جامعة السلطان قابوس، سلطنة التطنة عمان.

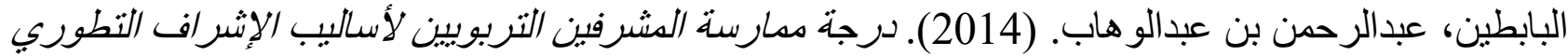

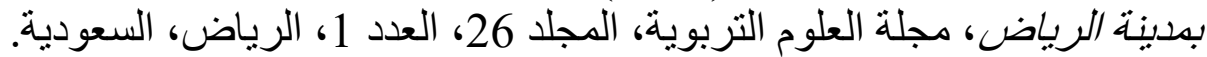

اللوح، أحمد حسن. (2012). درجة تحسين الإثراف التربوي التطوري للمدارسات التنربيسية لدعلمي اللغة

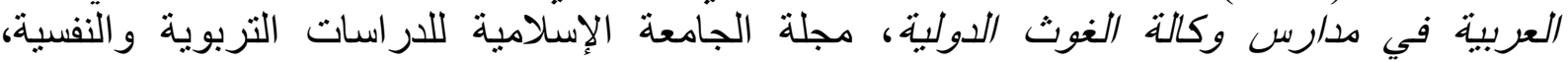

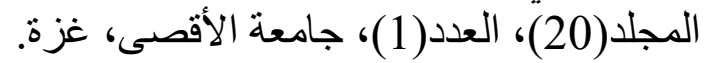

شديفات، يحيى وسليمان، القادري. (2005). أثر استخدام الإشراف التربوي التطوري في تحسبن المدارسات

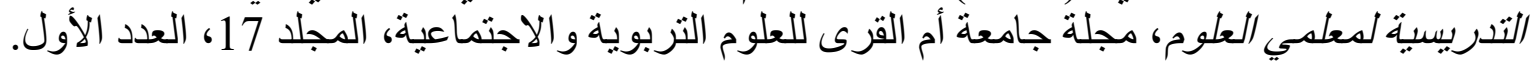

\section{ARABIC REFERENCES IN ROMAN ALPHABET}

Aleabadi, Eibdalaluh. (2009). Al'iishraf Altatawri, 'lidarat Al'iishraf Altarbwi, Jidat.

'Abu Eabid, Mahmawd. (2004). Almarjie fi Al'iishraf Waleamaliat Al'iishrafiati, Dar Alkitab Althaqafi,

Al'urdunn. Alqasim, Munsiwr. (2010). Dawr Mudiri Almadaris fi Tafeil Al'iishraf Altatwrii Bialmadaris Alhukumiat fi Muhafazat Jidat, Risalat Majstayr Ghyr Munshurin, Kuliyat Altarbiat - Jamieatan 'Ama Alquraa-.

Alkulbani, Yunis Bin Hamdan Bin Eabdallih. (2016). Madaa Mumarasat Almushrifin Altarbuiiyn Libaed 'Anmat Al'iishraf Altarbawii fi Madaris Altaelim Al'asasii Bimuhafazat Alwustaa Bisiltanat Eumaan, Risalat Majsatayr Ghyr Manshurat, Jamieat Nazwaa, Saltanat Omman.

Aldarushiu, Khamis Bin Saeid Bin Khamis. (2016). Darajat Mumarasat Almushrifin Alturbuiiyn Al'awayil 'Adwarahum Alwazifiat Bimuhafazat Janub Alsharqiat fi Saltanat Eumaan, Risalat Majsatayr Ghyr Manshurat, Jamieat Nazwaa, Saltanat Omman.

Albabtin, Eabdaleziz. (2005). Aitijahat Hadithat Fi Al'iishraf Altarbwi, Maktabat Aleubykan, Alriyad.

Altawbi, Eisaa. (2005). Alkifayat Al'adayiyat Allazimat Lilmushrifin Altarbuiiyn fi Saltanat Eamman Wamadaa Tumakinihim Minha, Risalat Majstayr Ghyr Manshuratin, Biruta: Jamieat Alqidiys Yusif.

Alhusni, Yahi Bin Seyd. (1999). Alaihtiajat Altadribiat Lilmushrifin Alturbuiiyn Kama Yaraha Almushrifun Walmuelimun fi Almadaris Alhukumiat Bisaltanat Eammana, Risalat Majstyr Ghyr Manshurati, Jamieat Alyrmwk,

Al'urduni . Alkhiari, Nasir Bin Rashid. (2002). Madaa Mumarasat Muajah Aldirasat Alaijtimaeiat Limihamih Alfaniyat Min Wijhat Nazar Almuealimin fi Saltanat Eumaan, Risalat Majsatayr Ghyr Manshurat, Jamieat Alsultan Qabaws, Saltanat Omman.

Alzahiri, Haydar Eabdalkrim. (2017). Manahij Albahth Altarbawii, Markaz Dibinu Litaelim Altfkyr Altbet1, Al'urdunn. Alrashidiu, 'librahim Eibdalluh. (2010). Taqyim Al'iishraf Altatwrii Min Wijhat Nazar Almuealimin fi Mintaqat Hayil Altaelimiat fi Almamlakat Alearabiat Alsaeudiati, Jamieatan Mutati, Bahath Majstayr Ghyr Munshur.

Shahin, Ebdalrhmn Ywsf. (2010). Faeiliat Tatbiq Al'iishraf Altarbuii Altatwirii Altasharukii fi Tahsin Almumarasat Altadrisiat Ladaa Muelimi Aleulumi, Risalat Dukturat Ghyr Manshurat, , Jamieatan 'Am 
Alquraa, Makat Almukramata, Almamlakat Alearabiat Alsaeudia

Shalash, Biaism Waharz Allah, Hasam. (2017). Al'iishraf Alturbawiu Waealaqatuh fi Altatawur Almahnii Limuelimi Alriyadiat.

Eatari, Earuf. (2005). Al'iishraf Alturbawiu Wanamadhijuh Alnazariat Waltatbiqiat Aleamaliatu, Maktabat Alfalahi, Alkuayt.

Alhumzani, Khalid Ghunim. (2009). Aitijahat Hadithat Fi Al'iishraf Altarbwii, Risalat Majstayr Ghyr Manshurati, Kuliyat Altarbiati, Jamieat Almalik Sueud.

Alyahmadi, Hamd Bin Hulal. (2005). Madaa Faeiliat 'Asalib Al'iishraf Almutabaqat fi Saltanat Eamman Min Wijhat Nazar Almuealimin Walmushrifina, Risalat Majstayr Ghyr Manshurati, Kuliyat Altarbiati, Jamieat Alyarmuk.

Wizarat Altarbiat Waltaelim. (2008). Dalil Al'iishraf Altarbwii, Masqatun, Matbueat Wizarat Altarbiat Waltaelim.

Aleufi, Muhamad Bin Eali. (2000). Waqie Al'iishraf Altarbuii Bialtaelim Aleami fi Saltanat Eamman Waitjihat Tatwirihi, Risalat Majstayr Ghyr Manshurati, Kuliyat Altarbiati, Jamieat Alsultan Qabus, Saltanat Omman.

Albabtin, Eabdalrhmin Bin Eabdaluhab. (2014). Darajat Mumarasat Almushrifin Altarbuiiyn Li'asalib Al'iishraf Altatwrii Bimadinat Alriyadi, Majalat Aleulum Altarbawiati, Almujalad 26, Aleadad 1, Alriyadu, Alsieudiat.

Allawhu, 'Ahmad Hasn. (2012). Darajat Tahsin Al'iishraf Alturbawii Altatawrii Lilmumarasat Altadrisiat Limuelimi Allughat Alearabiat fi Madaris Wikalat Alghawth Alduwliati, Majalat Aljamieat Al'iislamiat Lildirasat Altarbawiat Walnafsiati, Almajlda(20), Aleidda(1), Jamieat Al'aqsaa, Ghazat.

Shadifat, Yahyaa Wasuliman, Alqadri. (2005). 'Athar Aistikhdam Al'iishraf Altarbuii Altatawurii fi Tahsin Almumarasat Altadrisiat Limuelimi Aleulumi, Majalat Jamieat 'Am Alquraa Lileulum Altarbawiat Walaijtimaeiati, Almujalid 17, Aleadad Al'awl.

\section{REFERENCE LIST}

Gordon,s.(2000): Supervision of Instruction ADevelopmental Approach,Third Edition And, Bostos.

Mudawali \& Mudzofri (2017). Realationship BetweenInstructional supervision \& professional Development,Perceptions of secondary school Teachers \& MadarahTsanawitah (Islamic Secondary school ) Teachers inLhkseumawe, Aeeh, Indonesia ,Master of education Universityof Tampere. 